\title{
An Assessment of Usage and Physical Activity Patterns, Measurement of Satisfaction Indicators and Purpose of Visit at Two University Recreation Centers
}

Robin L. Yeager

West Virginia University

Follow this and additional works at: https://researchrepository.wvu.edu/etd

\footnotetext{
Recommended Citation

Yeager, Robin L., "An Assessment of Usage and Physical Activity Patterns, Measurement of Satisfaction Indicators and Purpose of Visit at Two University Recreation Centers" (2012). Graduate Theses, Dissertations, and Problem Reports. 3579.

https://researchrepository.wvu.edu/etd/3579

This Dissertation is protected by copyright and/or related rights. It has been brought to you by the The Research Repository @ WVU with permission from the rights-holder(s). You are free to use this Dissertation in any way that is permitted by the copyright and related rights legislation that applies to your use. For other uses you must obtain permission from the rights-holder(s) directly, unless additional rights are indicated by a Creative Commons license in the record and/ or on the work itself. This Dissertation has been accepted for inclusion in WVU Graduate Theses, Dissertations, and Problem Reports collection by an authorized administrator of The Research Repository @ WVU. For more information, please contact researchrepository@mail.wvu.edu.
} 


\title{
An Assessment of Usage and Physical Activity Patterns, Measurement of Satisfaction Indicators and Purpose of Visit at Two University Recreation Centers
}

\author{
Robin L. Yeager \\ Dissertation submitted to \\ the Davis College of Agriculture, Natural Resources and Design \\ at West Virginia University \\ in partial fulfillment of the requirements for the degree of
}

Doctor of Philosophy

in

Forest Resources Science

Robert C. Burns, Ph.D., Chair

Steven W. Selin, Ph.D.

Chad D. Pierskalla, Ph.D.

Jacqueline Webb-Dempsey, Ph.D.

Ernest Goeres, Ph.D.

\section{Morgantown, West Virginia \\ 2012}

Keywords: recreation, satisfaction, facilities, health, physical activity, college students 


\begin{abstract}
An Assessment of Usage and Physical Activity Patterns, Measurement of Satisfaction Indicators, and Purpose of Visit at Two University Recreation Centers
\end{abstract}

Robin L. Yeager

Research has demonstrated that building of student recreation/activity centers has been beneficial for university students who participate in informal recreation and programs during their out-of-class time. The utilization of an assessment tool created specifically to evaluate variables associated with usage and intention demonstrated that at vastly different university settings and type of recreation facilities, similar patterns suggested why university students are and are not utilizing the facilities that have been specifically built for their needs.

The first paper assessed usage and purpose of visit, and the importance of recreation and socialization in the setting of student recreation centers in university environments. The second paper examined a model of customer satisfaction of facilities, services and information and utilizing multiple regression statistics endeavored to predict overall satisfaction at two separate student recreation centers. Lastly, the third paper examined demographic characteristics of college students and investigated the relationships between these characteristics and physical activity patterns including reasons to exercise, attitudes toward physical activity and which variables would lead to the propensity to exercise vigorously.

Expanding on previous research, these findings will contribute to continuing research in the field of recreation and the importance of physical activity, recreation and socialization on university campuses. The three separate research articles shared a common theme of student interests and satisfaction with facilities on their campus. These findings indicate the need for management to continue to examine and assess the importance of physical activity, recreation and socialization in the setting of college environments. 


\section{ACKNOWLEDGEMENTS}

I would like to acknowledge the support of the West Virginia University Division of Forestry and the department of Recreation, Parks and Tourism Resources for the opportunity to continue my education and pursue this degree while also balancing full time employment.

I would like to thank my employer Fairmont State University for the financial support and flexibility to persist with this degree and support of my Vice President who encouraged me to fulfill my goal.

I would like to thank my committee members for their guidance and contributions. Dr. Jacqueline Webb-Dempsey helped me in understanding qualitative research as well as insight into character and behavior traits of student populations in a college environment. Dr. Ernest Goeres was instrumental both academically and professionally with the complexities of higher education finance. Dr. Steve Selin and Dr. Chad Pierskalla and their vast knowledge of recreation studies helped guide me to a greater appreciation and understanding of leisure science. I would like to especially thank my committee chair, Dr. Robert Burns for his ongoing support; he has been instrumental in my finishing this work through his continual guidance and direction. He has sustained me through personal tragedies, professional pressures and his resilience and belief in me has pushed me forward to complete this degree. I will be forever grateful to him.

In addition, I would like to thank my family members for the encouragement to persist, understanding when family time was neglected and their confidence in my abilities. I am continually inspired by my daughters and know they are proud of my achievement of this degree. 
Especially significant to the completion of this work was my husband Phil who never tired of listening to my ideas and frustrations, and patiently guiding, inspiring and supporting me every step until I finished this degree.

Lastly, I would like to dedicate this work to my departed parents (Charles and Lenore Allbaugh) who instilled in me the importance of learning and education, fortitude and perseverance; I know they would be proud of my accomplishment. 


\section{TABLE OF CONTENTS}

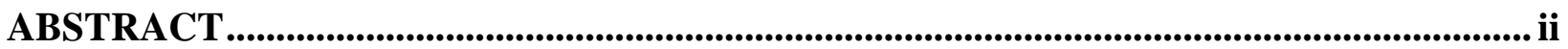

ACKNOWLEDGEMENTS ….......................................................................................... ii

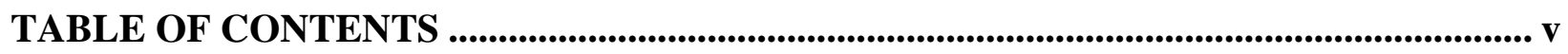

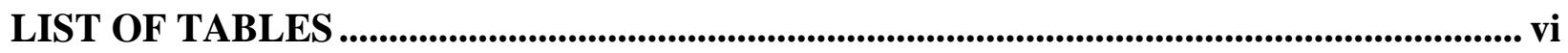

LIST OF FIGURES ................................................................................................................................ vii

CHAPTER 1: Introduction.................................................................................................................. 1

CHAPTER 2: PAPER 1 An Assessment and Comparison of Usage Patterns and Purpose of Visit of Campus Recreation Centers at Two Universities........................................................... 5

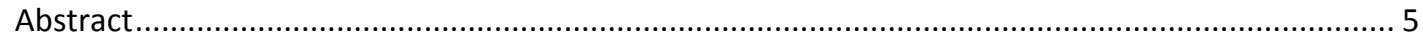

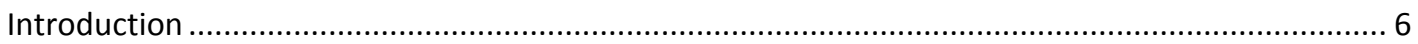

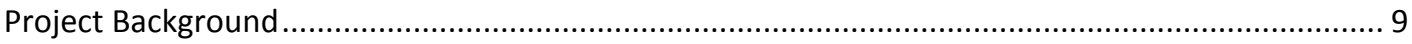

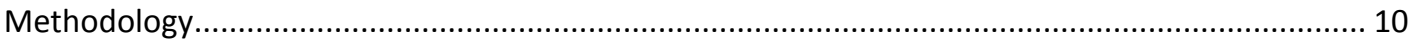

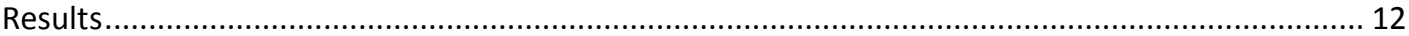

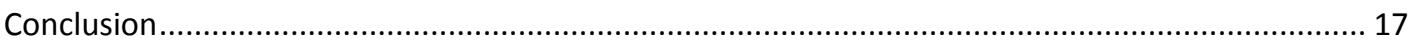

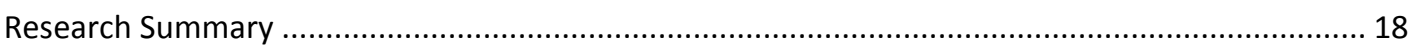

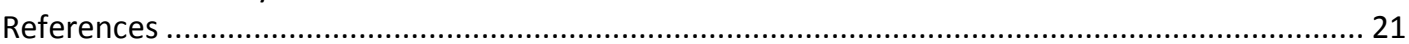

CHAPTER 3: PAPER 2 Satisfaction with Student Recreation Center Facilities, Services and Information: A Comparison of Two Universities.................................................................... 23

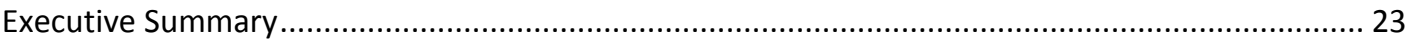

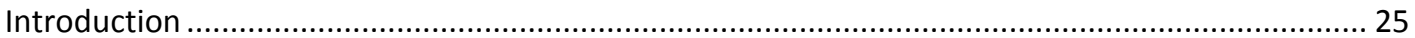

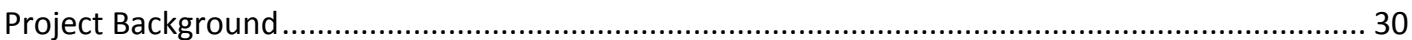

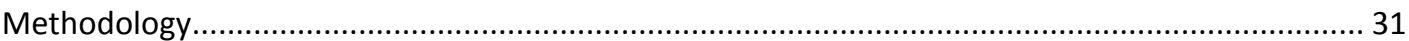

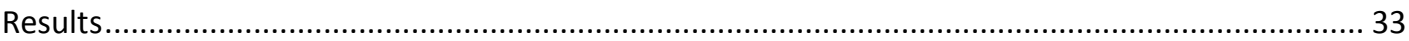

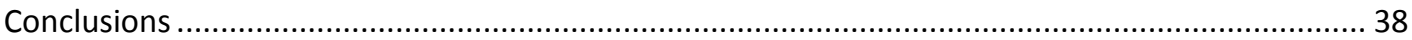

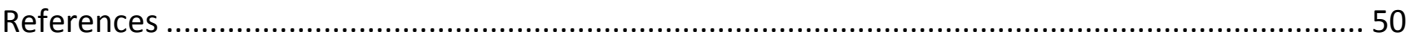

CHAPTER 4: PAPER 3 Similarities and Differences in Physical Activity among University Students

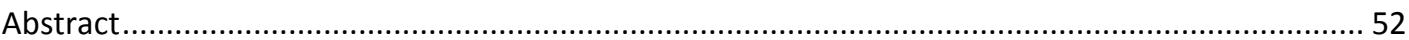

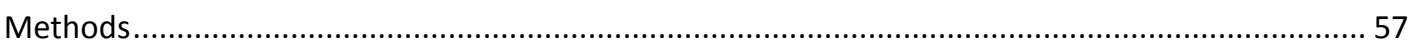

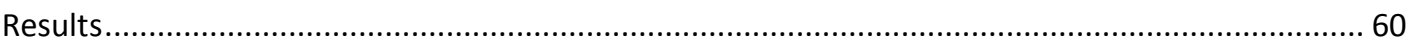

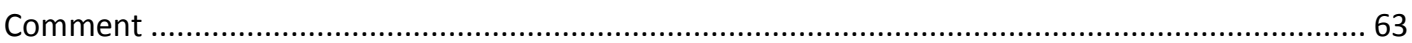

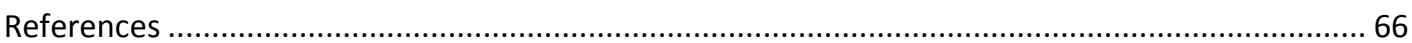

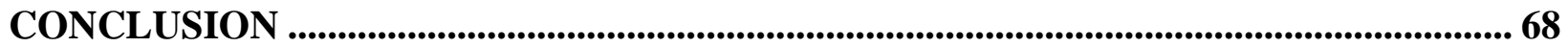

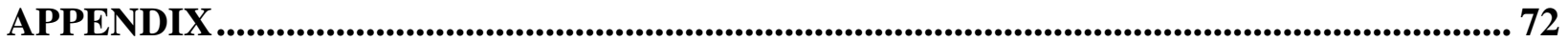

Fairmont State University Questionnaire .......................................................................... 72

Fairmont State University - Summary of Positive Comments ............................................... 80

Fairmont State University - Summary of Improvements .................................................... 81

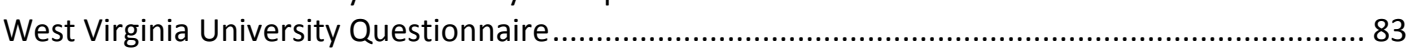

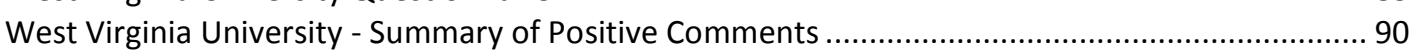

West Virginia University - Summary of Improvements .......................................................... 91 


\section{LIST OF TABLES}

Paper 1: An Assessment and Comparison of Usage Patterns and Purpose of Visit of Campus Recreation Centers at two Universities

Table 1. Socio-demographic characteristics ............................................13

Table 2. Reasons recreation/activity center is used ........................................... 15

Table 3. Rationale why the recreation/activity center was visited............................16

Table 4. Rationale why people may not utilize facility as often as wanted ......17

Paper 2: Satisfaction with Student Recreation Center Facilities, Services and Information: A Comparison of Two Universities

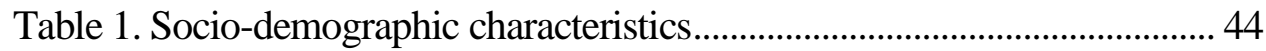

Table 2. Comparison of Mean Values for 15 items with domain and domain values ........................................................................ 45

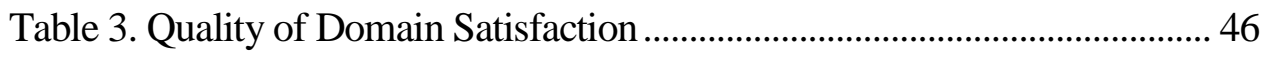

Paper 3: Similarities and Differences in Physical Activity among University Students

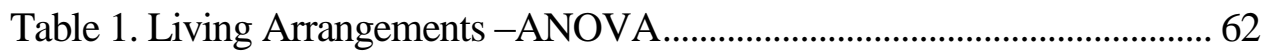

Table 2. Social or Physical - T-test..................................................................... 62 


\section{LIST OF FIGURES}

Paper 2: Satisfaction with Student Recreation Center Facilities, Services and Information: A Comparison of Two Universities

Figure 1. Conceptual Model of Customer Satisfaction ..............................................47

Figure 2. Customer Satisfaction Model: University A ................................................................ 48

Figure 3. Customer Satisfaction Model: University B .................................................................... 49 


\section{CHAPTER 1: Introduction}

The focus of this dissertation was to study two separate university recreation centers and understand student usage patterns, purpose of visit, comprehend similarities and differences in physical activity patterns among students and test a model of customer satisfaction of facilities, services and information. The result of this of research is demonstrated as three papers in Chapters Two, Three and Four. In each of the chapters, a common theme of student satisfaction, recreation and socialization emerges validating how use of the student recreation center contributes to a greater student satisfaction with their overall college experience.

The motivation behind this work stemmed from working at both university recreation centers and observing similar and different student needs, interests and patterns of recreation and socialization. A pilot questionnaire was administered at Fairmont State University and results showed there were specific questions that included complex tables that were frequently left unanswered. For this reason, the final survey instrument was simplified and edited for more thorough completion of tables and questions. The final survey was administered in October, 2008 and the study expanded to include both Fairmont State University and West Virginia University. Based on (Dillman, 2000) survey protocol, the format of a questionnaire can improve the response rate of a research study. The colorful booklet format was easy to read and on average each survey took approximately 10 minutes to complete. Dillman asserts that people's motivation to respond to surveys is vested in the Social Exchange Theory, which suggests that by responding to the survey, respondents will be compensated in return in a way that meets some of their needs (Dillman, 2000). The questionnaire queried participants about their usage patterns, purpose of visit and satisfaction associated with various facets of their 
recreation experience; this included facilities management, service provided by staff and a series of facility satisfaction measures. At both centers, tables were located in a central location adjacent to the primary ingress and egress points. Respondents were notified that the results of the study would be part of a doctoral dissertation and that the benefits of the study would be used to help improve recreation opportunities at the university. No personal information was collected that could link the student's identification to a completed survey. Participants were given a free non-alcoholic drink for completing the questionnaire to encourage participation. A total of 553 surveys were collected; 285 collected from West Virginia University and 268 surveys from Fairmont State University.

The first facility, West Virginia University, is a NCAA Division I, Land Grant University located in a small town of 28,600 . The university's population of 29,000 students doubles the size of the community. The university population ratio is $52 \%$ male and $48 \%$ female and 5,500 live in on-campus residence halls. The Student Recreation Center (SRS) began construction October, 1999 and was completed July, 2001. The new 177,000 square foot, \$34 million dollar recreation center is centrally located on 12 acres on the northern campus and is heavily used by many students. The SRS is located in close proximity to a large residential complex consisting of 2,500 freshmen students, with the intent of encouraging new student involvement and utilization of the facility.

The second facility, Fairmont State University, is a NCAA Division II university, also located in a small town of 19,000 people. The university has a population of 7,450 students, with 840 (nine percent) living in residence halls. The university population ratio is $57 \%$ female and $43 \%$ male. The $\$ 24$ million dollar student facility referred to as the Falcon Center opened in January, 2005 and is unique in that both a student recreation center and student union are housed 
in a 145,000 square foot facility. The facility, centrally located on campus, includes recreation and fitness areas, dining services, conference area, computer labs, student health services, copy center, and campus security.

Chapter Two of this dissertation examined the relationships between student usage and purpose of visit at the two separate and unique university student recreation centers. Recreation and socialization themes emerged as paradigms explaining pattern usage and purpose of visit. Similar patterns were presented for why university students are and are not utilizing the facilities that have been specifically built for their needs. To understand differences, if any, between the two separate university student populations, the respondents were asked a series of sociodemographic questions. To understand usage patterns and purpose of visit, questions were asked what the facilities were mostly used for; recreation, socialization or both. Respondents were also asked possible reasons why they visited the facilities and to explain the reason for visiting the center. Also of interest was why individuals may not utilize the recreation centers as often as they would like.

Chapter Three examined a model of customer satisfaction of facilities, services and information at both university student recreation centers. The Burns et al. (2003) recreational services model, using three of four domains (facilities, services, information) was replicated and extended for this study. The model included 15 satisfaction items across the three domains. Each domain included an overall measurement of satisfaction, and an additional overall measure of quality of experience was calculated. A series of multiple regression tests were employed to determine the relationships between satisfaction ratings and individual scores. Three hypotheses were examined; H1) differences in socio-demographics between the two universities, H2) differences in item and domain scores between the universities and, H3) prediction of items and 
domains to overall satisfaction within the two universities.

Chapter Four examined demographic and personal characteristics of a cohort of college students to understand the relationships between these characteristics and physical activity patterns. Physical activity patterns included how often students exercised per week, reasons to exercise, attitudes toward physical activity and which variables would lead to the propensity to exercise vigorously. The following objectives were addressed: 1) determine overall similarities and differences in demographics 2) summarize physical activity patterns of the college student population, 3) assess queried statements indicating reasons to use the facility in a cohort of college students 4) evaluate opinions toward exercise and ascertain which variables influenced physical activity. Various statistics were analyzed to understand these relationships, including independent samples t-tests and ANOVA. This research expanded on previous studies and indicates the need for management to continue to examine and assess the importance of physical activity, recreation and socialization in the setting of college environments.

Throughout this dissertation various statistics were utilized to predict and analyze results. Two separate questionnaires were administered as certain questions were unique to the individual campus recreation centers. Included in each administered questionnaire were two qualitative questions, "What positive comments do you have about the facility?", and "What improvements would you suggest for the facility"? The results of the qualitative questions were summarized and listed. These comments are helpful to management for future improvements. 


\title{
CHAPTER 2: PAPER 1
}

\section{An Assessment and Comparison of Usage Patterns and Purpose of Visit of Campus Recreation Centers at Two Universities}

\begin{abstract}
The purpose of this study was to examine the relationships between student usage and the purpose of visit at two separate and unique university student recreation centers. Research has demonstrated that building of student recreation/activity centers has been beneficial for the college student who participates in programs and informal recreation during their out-of-class time. Recreation and socialization themes emerge as paradigms explaining pattern usage and purpose of visit. The utilization of an assessment tool created specifically to evaluate variables of usage and intention demonstrated that at vastly different college settings and type of recreation buildings, similar patterns were presented for why university students are and are not utilizing the facilities that have been specifically built for their needs. This research expands on previous studies and indicates the need for management to continue to examine and assess the importance of physical activity, recreation and socialization in the setting of college environments.
\end{abstract}

Keywords: facilities, recreation, satisfaction 


\section{Introduction}

This study examined the relationships between student usage and the purpose of visit at two university student centers located in the South Atlantic region of the United States. University A, a large Division I school and its student recreation center, and University B, a smaller university and its student activity center were both evaluated for this study.

Over the past 30 years a new type of facility has emerged at colleges and universities across the United States. These buildings have been called student recreation centers, student activity centers, or centers for physical activities (Body, 1996). Many universities nationwide have hired recreational consultants to assess campus recreation needs, communicate with student focus groups with the goal of developing elaborately designed new or renovated buildings. Student values, interests and needs have also necessitated the building of campus recreation facilities as universities have begun to recognize the competition among college campuses to recruit and retain students. The clear message is that universities need to offer quality activities and facilities to enrich student life to incoming and returning students. Steinbach (2000) noted that recognition of recreation as a tool in student recruitment and retention became widespread in the 1990's. This is particularly important on residential universities where on-campus recreation alternatives may help students develop both socially and physically.

The benefits of participation in out-of-class activities has been extensively studied (Belch, Gebel, \& Mass, 2001; Little \& Guse, 1988; Tsigilis, Masmanidis \& Koustelios, 2009; Turman \& Hendel, 2004). Activities integrating students into the social community of campus facilitate a greater student satisfaction with their overall college experience. Astin (1984) stated the general belief of colleges is that extra-curricular and recreational activities contribute to student development, enhance the undergraduate experience and increase the involvement in 
learning. Recreation on college campuses traces its roots to the early twentieth century (Lewis, Jones, Lemke, \& Dunn, 1998). As schools began to develop athletic departments in the early 1900's, administrators realized that a significant population did not participate in intercollegiate athletics. Intramural and club sports became popular, but there also existed a need for informal recreation or the ability to recreate without organization. The students needed facilities focused toward recreational free play; a place where student involvement was not associated with athletics or physical education curriculum.

Astin (1984) studied student involvement in higher education, and identified indicators in the college environment that significantly affect the student's persistence in college. This theory of student involvement includes student participation and refers to "the amount of physical and psychological energy that the student devotes to the academic experience" (Astin, p. 298). One of the important factors predicting college involvement was the student's participation in extracurricular activities of almost any type. Turman and Hendel (2004) examined students' involvement utilizing survey responses prior to and after the opening of a recreation center. This study investigated the impact on involvement, satisfaction and perceived benefits before and after construction of new recreation facilities. The authors were also interested in the perceived benefits of participation in recreational activities and interaction between students, academic staff, administrators and recreation staff. The conclusions of the study were varied; significant increases in participation occurred in fitness activities, but not an overall increase in student involvement or satisfaction in all programs. High levels of satisfaction with indoor facilities across all independent variables did not translate into high levels of satisfaction with recreation programs and activities.

A recent study conducted by the National Intramural Recreation and Sport Association 
(NIRSA) showed that heavy users of campus recreational programs and activities identified their participation as one of the key determinants of college satisfaction and success (Downs, 2003). The NIRSA study found a direct correlation between a level of participation and happiness with college experiences as well as additional benefits of reduced stress and improved emotional wellbeing. Out of 21 factors determining college satisfaction and success, the value of recreational sports ranked $11^{\text {th }}$.

The role of a campus recreation center in creating a community has also been investigated. Dalgarn (2001, p. 68) suggested such centers are "a place to meet friends, hang out, and see and be seen." The recreation center has become the center of many campuses and can play a significant role in establishing a sense of kinship among the students, faculty and staff. Viklund and Damin (2002) discussed the combining of collegiate facilities for student recreation and student life as the wave of the future.

A typical facility is open 16 or more hours a day and offers a variety of programs and activities for students, employees and the outside community. It is the challenge of management to set goals and objectives pertinent to meet the needs and expectations of several diverse groups. Social activities, fitness and wellness classes, outdoor adventures, intramurals and sport clubs tend to be the programs that are most popular. Such programs fulfill the needs of the student and employee communities, while summer camps and special events create additional revenue and offer programs to the outside community. It has been suggested that "recreation may constitute the single most common experience of college students" (Bryant, Banta, \& Bradley, 1995, p. 159).

Characteristics of users and non-users of campus recreation centers were studied to determine the predictors of facility usage (Miller, Noland, Rayens \& Staten, 2008). These 
authors examined recreation center usage by undergraduate students and assessed the personal and demographic factors that were predictive of recreational use. Utilizing logistic regression modeling they confirmed their results were consistent with other research, "that the profile of a typical recreation-center user is a physically active, younger man who lives on campus and belongs to a fraternity" (Miller, et al., p. 94).

Previous research also identified benefits achieved from participating in university recreation, including holistic wellness, personal and social diversity enhancement and leadership skills (Haines, 2001; Nesbitt, 1993).

Several authors have researched the impact of student campus recreation centers, suggesting students are generally satisfied with their experiences by utilizing standard assessment tools to measure accountability and effectiveness (Cavanar, Kirtland, Evans, Wilson, Williams, Mixon, \& Henderson 2004; Howat, Absher, Crilley \& Milne 1996; Kovac \& Beck, 1997; Zizzi, Ayers, Watson, \& Keeler 2004).

\section{Project Background}

University A (UA) is a NCAA Division I, land grant university located in a small town of 28,600. The university's population of 29,000 students doubles the size of the community. The university population ratio is 52\% male and $48 \%$ female and 5,500 live in on-campus residence halls. The Student Recreation Center (SRS) began construction October, 1999 and was completed July 2001. The new 177,000 square foot, $\$ 34$ million dollar recreation center is centrally located on 12 acres on the northern campus and is heavily used by many students. The SRS is located in close proximity to a large residential complex consisting of 2,500 freshmen students, with the intent of encouraging new student involvement and utilization of the facility. University B (UB), a NCAA Division II university, is also located in a small town of 
19,000 people. The university has a population of 7,450 students, with 840 (nine percent) living in residence halls. The university population ratio is $57 \%$ female and $43 \%$ male.

The UB student facility opened in January, 2005 and is unique in that both a student recreation center and student union are housed in a 145,000 square foot facility. The facility, centrally located on campus, includes recreation and fitness areas, dining services, conference area, computer labs, student health services, copy center, and campus security.

\section{Methodology}

In October 2007, a pilot study was administered at University B's Student Activity Center (SAC). A total of 68 pilot surveys were returned and analyzed. The pilot study included complex tables that were frequently left unanswered, for this reason the final survey instrument was simplified and edited for more thorough completion of tables and questions.

The final survey was administered in October, 2008 and the study was expanded to include both University A and University B. These two university facilities were selected as they were located within 30 miles of each other; the facilities are unique to their campuses and diverse groups of students. At both centers, tables were located in a central location adjacent to the primary ingress and egress points. Respondents were notified that the results of the study would be part of a doctoral dissertation and that the benefits of the study would be used to help improve recreation opportunities at the university. On average, each survey took approximately 10 minutes to complete. No personal information was collected that could link the student's identification to a completed survey. Participants were given a free non-alcoholic drink for completing the questionnaire to encourage participation. The questionnaire queried participants about their usage patterns, purpose of visit and satisfaction associated with various facets of their recreation experience. This included facilities management, service provided by staff, and a 
series of facility satisfaction measures. Surveys were collected at both institutions on three different days and times to ensure the sample included as diverse group of respondents as possible. A total of 553 surveys were collected, with 285 collected from UA and 268 surveys from UB.

To understand differences, if any, between the UA and UB students, the respondents were asked a series of socio-demographic questions such as living status, years in college, etc. To understand the usage patterns and purpose of visit, questions were asked what the facilities were mostly used for; recreation, socialization or both. A follow-up question asked the students how often they visited the center in a typical week. Respondents were asked possible reasons why they visited the facilities and to explain the reason for visiting the center. Possible reasons included for physical exercise, to lose weight, reduce stress, to be with friends and other rationale. This set of questions was rated on a Likert scale ranging from 1 (Awful) to 5 (Excellent) explaining the reasons for achieving their goals in visiting the center. Also of interest was why individuals may not utilize the recreation centers as often as they would like. To understand these reasons a scale of 1 (Major reason), 2 (Minor reason), 3 (Not a reason) and an answer of not sure or don't know was used. Many available causes were included such as being too busy, not enough time to exercise, too tired to exercise, no motivation, hours of facility not convenient, no way to get there and several more items. 


\section{Results}

Overall, male students $(56.6 \%)$ made up a majority of the respondents. UA respondents were more likely to be male $(65.9 \%)$ and UB more likely to be female (53.4\%). The vast majority of respondents $(90.3 \%)$ were White, full-time students $(97.8 \%)$ with 12 or more credit hours. Just over half of the respondents (52.7\%) did not work and almost half (47.3\%) lived in off campus housing. Significant differences regarding race were noted between the students at UA and UB. The vast majority of students at UA reported their racial background as White (94.3\%) compared to just $85.9 \%$ at UB. University B was about four times as likely to include Asian students $(7.6 \%)$ than UA $(1.8 \%)$. Also, the UB student population included twice as many Black students $9.2 \%$, compared to just $4.3 \%$ at UA. There was no significant difference in the Hispanic population between the universities. Enrollment status was similar between the universities, with UA having $98.9 \%$ full time and 1.1\% part time students, and UB having $96.6 \%$ full time and $3.4 \%$ part time students. Student employment status between the colleges was significantly different, with UA having $57.3 \%$ not working, $35.1 \%$ working part time and $7.5 \%$ working full time. UB was somewhat different, with $47.7 \%$ not working, $38.2 \%$ working part time and $14.1 \%$ working full time.

Overall, one third of the respondents $(33.1 \%)$ were first year students, $21.6 \%$ second year students, $18.5 \%$ third year students and $26.8 \%$ were in their fourth or higher year. The results were significantly different between students at the two universities, with about half (49.6\%) of UA students being in their first or second years, compared to $60.3 \%$ of UB students. 
Table 1: Socio-demographic characteristics

\begin{tabular}{|c|c|c|c|c|}
\hline Characteristics & UA & UB & Overall & Test Statistic \\
\hline \multicolumn{5}{|l|}{ Gender \% } \\
\hline Male & 65.9 & 46.6 & 56.6 & \\
\hline Female & 34.1 & 53.4 & 43.4 & $\chi^{2}=20.665^{* * *}$ \\
\hline \multicolumn{5}{|l|}{ Ethnicity \% } \\
\hline White & 94.3 & 85.9 & 90.3 & $\chi^{2}=11.024 * * *$ \\
\hline Black & 4.3 & 9.2 & 6.6 & $\chi^{2}=5.288 * *$ \\
\hline Asian & 1.8 & 7.6 & 4.6 & $\chi^{2}=10.639 * * *$ \\
\hline Hispanic & 13.2 & 15.0 & 14.0 & \\
\hline \multicolumn{5}{|l|}{ Enrollment Status \% } \\
\hline Full time $(12+$ credits $)$ & 98.9 & 96.6 & 97.8 & \\
\hline Part time ( $<12$ credits $)$ & 1.1 & 3.4 & 2.2 & $\chi^{2}=3.375$ \\
\hline \multicolumn{5}{|l|}{ Years in College \% } \\
\hline $1^{\text {st }}$ year & 25.2 & 41.8 & 33.1 & \\
\hline $2^{\text {nd }}$ year & 24.4 & 18.5 & 21.6 & $\chi^{2}=16.570 * * *$ \\
\hline $3^{\text {rd }}$ year & 19.6 & 17.3 & 18.5 & \\
\hline $4^{\text {th }}$ year and higher & 30.7 & 22.5 & 26.8 & \\
\hline \multicolumn{5}{|l|}{ Employment Status \% } \\
\hline Works full time & 7.5 & 14.1 & 10.7 & \\
\hline Works part time & 35.1 & 38.2 & 36.6 & $\chi^{2}=8.206^{*}$ \\
\hline Does not work & 57.3 & 47.7 & 52.7 & \\
\hline \multicolumn{5}{|l|}{ Living while in School \% } \\
\hline Dorms/campus apartments & 23.6 & 43.7 & 33.3 & \\
\hline Off campus housing & 68.6 & 24.5 & 47.3 & $\chi^{2}=1.117 * * *$ \\
\hline Home & 7.9 & 31.8 & 19.4 & \\
\hline
\end{tabular}

Note. ${ }^{*} \mathrm{p}<.05, * * \mathrm{p}<.01, * * * \mathrm{p}<.001$.

A series of questions were asked examining the reasons for using the recreational

facilities. Overall, nearly one half $(48.8 \%)$ of respondents utilized the centers for recreation,

$38.2 \%$ for both recreation and socialization, and just $11.4 \%$ for socialization only. The

distribution varied between schools, with UA students much more likely to report recreation

(71.4\%) and about one quarter (24.6\%) reporting both socialization and recreation, and just $1.1 \%$ 
for socialization. UB students were more likely to use the facility for both recreation and socialization $(53.9 \%)$ than for recreation only $(21.9 \%)$ and $22.7 \%$ for socialization. When the question was asked, "What is the primary reason for using the recreation/activity center," significant differences were noted between the university settings. UA students used the facility predominantly for physical exercise $(80 \%)$, to lose weight (11.6\%) and to be with friends $(1.1 \%)$. Conversely, less than half $(45.8 \%)$ of UB respondents reported they were using the facility solely for physical exercise. Over one third of UB students (34.3\%) said their motivation was to be with friends, and a small minority (7.6\%) said they were using the facility to lose weight. When asking the number of times in a typical week the participant utilized the facility for socialization or recreation, the overall mean was evenly distributed with 3.91 visits for socialization and 3.74 visits for recreation. Respondents at UB were much more likely to report they visited for socialization (6.16 visits per week) than UA students (1.79 visits per week). Conversely, UA students reported a slightly higher number of visits per week for recreation (4.12 visits per week) than UB (3.3 visits per week). 
Table 2: Reasons the recreation/activity center is used

When using the Recreation Center, do you usually use it for socialization, recreation, or both?

\begin{tabular}{|l|l|l|l|}
\hline Reasons & UA\% & UB \% & Overall \% \\
\hline Recreation & 71.4 & 21.9 & 48.8 \\
Socialization & 1.1 & 22.7 & 11.4 \\
$\chi^{2}=1.52^{* * *}$ & 24.6 & 53.9 & 38.2 \\
\hline
\end{tabular}

What is the primary reason for using the recreation/activity center?

\begin{tabular}{|l|l|l|l|}
\hline Reasons & UA\% & UB\% & Overall\% \\
\hline For physical exercise & 80 & 45.8 & 63.7 \\
Be with friends in my group & 1.1 & 34.3 & 16.9 \\
To lose weight & 11.6 & 7.6 & 9.7 \\
Other & 7.3 & 12.4 & 9.7 \\
$\mathrm{X}^{2}=1.151 * * *$ & & & \\
\hline
\end{tabular}

In a typical week, how often do you, 1) visit the facility for socialization, or 2) for at least 30 minutes of recreation?

\begin{tabular}{|l|l|l|l|l|}
\hline & UA Mean & UB Mean & Overall Mean & T-test Statistic \\
\hline Recialization & 1.79 & 6.16 & 3.91 & $71.501^{* * *}$ \\
Recreation & 4.12 & 3.30 & 3.74 & $4.215^{*}$ \\
\hline
\end{tabular}

Note. $* \mathrm{p}<.05, * * * \mathrm{p}<.001$.

Understanding the reasons why students visited the recreation centers was an important question in this study. Results showed significant differences for five of the nine reasons, with UA reporting higher or equivalent mean scores than UB for all but one item. UB students were more likely to report they were visiting to be with friends in my group ( $U B=4.03, U A=2.97$ ). 
UA students were significantly more likely to report higher mean scores for the following items: for physical exercise $(\mathrm{UA}=4.68, \mathrm{UB}=3.93)$, to reduce stress $(\mathrm{UA}=4.10, \mathrm{UB}=3.58)$, to lose weight $(\mathrm{UA}=4.03, \mathrm{UB}=3.50)$, and to get away from the usual demands of life $(\mathrm{UA}=3.68, \mathrm{UB}$ $=3.25)$.

Table 3: Rationale why the recreation/activity center was visited

\begin{tabular}{|l|l|l|l|l|}
\hline Reasons & $\begin{array}{l}\text { UA } \\
\text { Mean }\end{array}$ & $\begin{array}{l}\text { UB } \\
\text { Mean }\end{array}$ & $\begin{array}{l}\text { Overall } \\
\text { Mean }\end{array}$ & F-Value \\
\hline To be with friends in my group & 2.97 & 4.03 & 3.48 & $95.60^{* * *}$ \\
For physical exercise & 4.68 & 3.93 & 4.33 & $80.91^{* * *}$ \\
To reduce stress & 4.10 & 3.58 & 3.85 & $29.04 * * *$ \\
To lose weight & 4.03 & 3.50 & 3.78 & $23.12^{* * *}$ \\
To get away from the usual demands of life & 3.68 & 3.25 & 3.48 & $16.95^{* * *}$ \\
To get away from other people & 3.03 & 2.86 & 2.95 & 2.079 \\
Other & 4.44 & 4.34 & 4.38 & .084 \\
To reflect on my spiritual values & 2.31 & 2.30 & 2.30 & .002 \\
For relaxation & 3.56 & 3.56 & 3.56 & .000 \\
\hline
\end{tabular}

Note. Scale: 1=Awful to $5=$ Excellent. In order of F-Value significance $* * * p<.001$.

Finally, participants were asked why they may not utilize the facility or participate as often as wanted. The most important reason for not participating as often as desired for respondents at both universities was "don't have enough time to exercise" ( mean $=1.92)$. Significant differences were noted for eight of the 20 constraints items, with respondents at UB reporting a higher level of constraints for five of the eight items that showed differences. These included, "I am unknowledgeable about how to use the equipment, I get plenty of exercise at my job, the hours of the facility are not convenient, fear of injury, and negative attitudes from employees." UA respondents reported a higher level of constraints for three of the eight items. These included, "too crowded, too far away and have no way of getting there." 
Table 4: Rationale why people may not utilize the facility as often as wanted

\begin{tabular}{|l|l|l|l|l|}
\hline Reasons & $\begin{array}{l}\text { UA } \\
\text { Mean }\end{array}$ & $\begin{array}{l}\text { UB } \\
\text { Mean }\end{array}$ & $\begin{array}{l}\text { Overall } \\
\text { Mean }\end{array}$ & F-Value \\
\hline Too crowded & 2.05 & 2.57 & 2.30 & $65.961^{* * * *}$ \\
Too far away & 2.52 & 2.79 & 2.65 & $23.101^{* * *}$ \\
Have no way to get there & 2.60 & 2.80 & 2.69 & $14.786^{* * * *}$ \\
Fear of injury & 2.85 & 2.70 & 2.77 & $9.795^{* * *}$ \\
The hours of facility are not convenient & 2.77 & 2.61 & 2.69 & $9.181^{* *}$ \\
Plenty of exercise at my job & 2.75 & 2.60 & 2.68 & $7.785^{* *}$ \\
Negative attitudes from employees & 2.87 & 2.75 & 2.82 & $6.725^{* *}$ \\
I am unknowledgeable about how to use equipment & 2.66 & 2.53 & 2.60 & $4.870^{*}$ \\
I feel intimidated due to body image & 2.59 & 2.47 & 2.53 & 3.636 \\
Lack of information about recreation opportunities & 2.82 & 2.76 & 2.79 & 1.603 \\
Don't have anyone to go with & 2.47 & 2.40 & 2.44 & 1.128 \\
Poor health & 2.73 & 2.67 & 2.70 & .963 \\
I don't have the motivation to exercise & 2.43 & 2.37 & 2.40 & .901 \\
Fear of prejudice based on my racial/ethnic identity & 2.81 & 2.77 & 2.79 & .665 \\
To busy with other recreation activities & 2.34 & 2.39 & 2.36 & .517 \\
Recreation that I like to participate in are not available & 2.72 & 2.68 & 2.70 & .463 \\
Like to do other things for recreation more & 2.44 & 2.46 & 2.45 & .097 \\
Not aware of recreation opportunities at facility & 2.78 & 2.77 & 2.78 & .034 \\
Don't have enough time to exercise & 1.91 & 1.92 & 1.92 & .032 \\
I am too tired to exercise & 2.36 & 2.36 & 2.36 & .008 \\
& & & & \\
\hline
\end{tabular}

Note. Scale: 1=Major reason, 2=Minor reason, $3=$ Not a reason. In order of F-Value significance $* \mathrm{p}<.05, * * \mathrm{p}<.01, * * * \mathrm{p}<.001$.

\section{Conclusion}

Although located less than 30 miles from one another, UA and UB are vastly different universities in size and character. UA has separate buildings for a student recreation center and student union, whereas UB has a combined facility which includes both a student union and recreation center. Significant differences were noted for nearly all of the social demographics at the two universities. UA respondents were predominately White, and were much more likely to be male, UB students were more likely to be part time students, more likely to be employed, and more likely to be first or second year students. UB students were also much more likely to live in a dormitory or at home, while UA students were much more likely to live in off-campus 
housing. These findings show the depth and breadth of the differences in the socio-demographic makeup of the students who utilize the two facilities. Use patterns as well showed distinct differences between these two student groups. UA students were much more likely to report they used the facility for recreation only, while UB students were more likely to use the facility for both recreation and socialization. This supports research by Viklund and Damin (2002) that suggests integration of student recreation and student union centers establishes a kinship and socialization among students. UA students were much more likely to report they used the facility for physical exercise than UB students, and UB students participated at the facility for socialization reasons about six times as much as UA students. Similar to what is found in the literature, the most constraining item was a lack of time to exercise. For those items showing significant differences, UA students were most likely to be constrained by items related to distance from their housing. This is a logical conclusion, as many of the UA respondents live in off-campus housing.

This would lead to the conclusion that regardless of the type of facility, similar types of students recreate and socialize on college campuses at their perspective student recreation/activity centers. Differences were noted for UA and UB on reasons why the students used their facilities. Students at UA were significantly more likely to utilize their center strictly for physical activity and recreation and very little for socialization, whereas UB students, with a combined recreation center and student union, were more likely to use the facility for both socialization and recreation.

\section{Research Summary}

University administrators have begun to recognize the significance of how students utilize their out-of-class time. It is important that students feel connected to their campus and 
social community, and student centers have proven to be beneficial to the overall college experience, be if for recreation only, socialization only, or both.

With the construction of the student activity center which includes both recreation and student union facilities for UB, a social environment attracted students to the facility. Students could then observe friends exercising and recreating and consider joining them. This study established that students at the university with two separate facilities visited the recreation center primarily for exercise. To encourage the building of community, social events should be proposed to take place at the recreation center.

Prior to construction, academic administration typically assess the requests of students and their physical and social needs. It is recommended that administrators conduct a follow-up study to understand why their students are or are not utilizing the facilities. The purpose of this research was to examine the relationships between student usage and the purpose of the visit. In a broad sense, recreation and socialization are demonstrated to be reasons to visit and participate. The most popular reasons why both facilities were visited were for physical exercise, to lose weight, to be with friends, to reduce stress and to get away from the usual demands of life. All of these categories can be attributed to physical, recreation and social needs. When asking why individuals may not utilize the facility, similar trends found in recreation research emerged. Overall, research findings for both UA and UB indicate that students do not have enough time or are too tired to exercise; they lack motivation to exercise, are busy with other activities or disdain a crowded facility. When comparing the two universities, other reasons were also significant, including "too far away," "no way to get there," and "the hours of the facility are not convenient." Modern facilities, innovative and varied programs, and friendly and creative staff are integral to the success of the recreation needs of the university student. For managerial 
purposes and implications, recreation administration should continually assess their students to determine if they are utilizing the facilities that have been specifically built for their needs.

Further investigation, follow-up surveys and evaluations are integral in the field of recreation for both researchers and management to continually evaluate trends, needs and responses of student participants. 


\section{References}

Astin, A.W. (1984). Student involvement: A developmental theory for higher education. Journal of College Student Personnel, 25, 297-308.

Belch, H.A., Gebel, M. \& Mass, G.M. (2001). Relationship between student recreation complex use, academic performance, and persistence of first-time freshmen. NASPA Journal, 38(2), 254-266.

Body, D. (1996). The outburst of student secreation centers. Planning for Higher Education, 25, 7-13.

Bryant, J.A., Banta, T.W., \& Bradley, J.L. (1995). Assessment provides insight into the impact and effectiveness of campus recreation programs. NASPA Journal, 32(2), 153-160.

Cavnar, M.M., Kirtland, K.A., Evans, M.H., Wilson, S.K., Williams, J.E., Mixon, G.M., \& Henderson, K.A. (2004). Evaluating the quality of recreation facilities: Development of an assessment tool. Journal of Park and Recreation Administration, 22(1), 96-114.

Dalgarn, M.K. (2001). The role of the campus recreation center in creating a community. NIRSA Journal, 25(1), 66-72.

Downs, P. E. (2003). Value of recreational sports on college campuses. Recreational Sports Journal, 27(1), 5-64.

Haines, D.J. (2001). Undergraduate student benefits from university recreation. Recreational Sports Journal, 25(1), 25-33.

Howat, G., Absher, J., Crilley, G., \& Milne, I. (1996). Measuring customer service quality in sports and leisure centres. Managing Leisure, 1, 77-89.

Kovac, D.C. \& Beck, J.E. (1997). A comparison of student perceptions, satisfaction and patterns of participation in recreational sports. NIRSA Journal, 22, 10-12.

Lewis, J.B., Jones T.R., Lamke, G. \& Dunn, J.M. (1998). Receational sport: Making the grade on college campuses. Parks and Recreation, 33(12), 72-78.

Little, S. L. \& Guse, D. (1988). Campus recreation services; An enterprise in higher education. Journal of Physical Education, Recreation and Dance, 59(8), 62-63.

Miller, K.H., Noland, M., Rayens, M.K., \& Staten, R. (2008). Characteristics of users and nonusers of a campus recreaiton center. Recreational Sports Journal, 32(2), 87-96. 
Nesbitt, G. (1993). What effect do our programs have on our participants? NIRSA Journal, 17, 16-18.

Tsigilis, N., Masmanidis, T., \& Koustelios, A. (2009). University students' satisfaction and effectiveness of campus recreation programs. Recreational Sports Journal, 33(1), 65-76.

Turman, J. C. \& Hendel, D. D. (2004). Changes in students' recreation activities, satisfaction and perceived benefits following the construction of a new recreational acility. Recreational Sports Journal, 28(2), 42-59.

Viklund, R. V. \& Damon, D. L. (2002). Centers of attention; combining collegiate facilities for student life and recreation may be the wave of the future. Athletic Business, 119-124.

Zizzi, S., Ayers, S. F., Watson, J. C., \& Keeler, L. A. (2004). Assessing the impact of new student campus recreation centers. NASPA Journal, 41(4), 588-630. 


\section{CHAPTER 3: PAPER 2}

Satisfaction with Student Recreation Center Facilities, Services and Information: A Comparison of Two Universities

\section{Executive Summary}

This study examined a model of customer satisfaction of facilities, services and information at two separate and unique university student recreation centers. Previous research has shown that satisfaction is often based upon the characteristics of services and how they are delivered. SERVQUAL, a service quality model developed by Parasuraman, Zeithaml and Berry and used often in consumer behavior field was the theoretical foundation. The RECQUAL customer satisfaction model (Howart, Absher, Crilley \& Milne, 1996), a derivation of SERVQUAL, was also used to explain recreation attributes important to recreation center settings. The Burns et al. (2003) recreational services model, using four domains (facilities, services, information, and recreation experience), was replicated and extended for this study. The Recreation Experience domain was removed, as its attributes were directed specifically toward customers in outdoor recreation settings. The model included 15 satisfaction items across the three domains. Each domain included an overall measurement of satisfaction, and an additional overall measure of quality of experience was calculated. A series of multiple regression tests were employed to determine the relationships between satisfaction ratings and individual scores. The dependent variables included measures of both overall and domain specific satisfaction, while the independent variables were measures of satisfaction of individual

attributes within each domain. Three research questions were examined; 1) differences in sociodemographics between the two universities, 2) differences in item and domain scores between the universities and, 3) prediction of items and domains to overall satisfaction within the two 
universities.

Results indicated a difference in demographics between two cohorts of students pertaining to gender, ethnicity, enrollment and employment status, number of years in college, and housing. Mean values of items and ratings of domains in the facilities, services and information measured significant between the two institutions, and, lastly customer satisfaction accounted for about $34 \%$ (UA) about $57 \%$ (UB) of variance in the overall quality of experience.

Student Recreation Centers are located on many college campuses and little research has been done to evaluate facility customer satisfaction. Managerial and professional staff will recognize the importance of assessing student satisfaction with facility items, services of staff, and information relevant to the student center.

Keywords: facilities, recreation, satisfaction 


\section{Introduction}

This study examined a model of customer satisfaction among participants at two university recreation centers on two separate universities. Theoretical foundation was developed from a service quality model (SERVQUAL), developed by Parasuraman, Zeithaml, and Berry $(1985,1988)$ and more recent studies of quality service in similar environments. The study explores service quality indicators as predictors of customer satisfaction and includes an examination of relationships within the model. Further speculation hypothesizes how the model's attributes and domains represent satisfaction. The extent to which the selected items and domains predicted overall satisfaction and an analysis of how the predictive model of customer satisfaction would vary for two user groups will be discussed.

Satisfaction in the field of recreation has been widely studied and can be defined in many ways (Burns, Graefe \& Absher, 2003). Facility and service managers, as well as market and academic researchers focusing on satisfaction and measurement are challenged by a plethora of options used in determining quality in recreation. Marketing researchers have examined customer satisfaction extensively (Burns, Graefe, \& Absher, 1997; Howart, Absher, Crilley, \& Milne, 1996; MacKay \& Crompton, 1990; Oliver, 1981; Shonk, Carry, \& DeMichele, 2010; Tsigilis, Masmanidis, \& Koustelios, 2009), and the SERVQUAL process (Parasuraman, Zeithaml, \& Berry, 1985, 1988) is a widely known model used often in the field of customer satisfaction. The SERVQUAL model of service quality assessed customer satisfaction across four non-recreation service industries; banking, credit card companies, security brokerage firms and product manufacturers. The construct of quality in this model is a comparison of consumer's perceptions and expectations of a service. Perceived quality is the consumer's judgment about an entity's overall excellence or superiority (Zeithaml, 1987). The distinction between attitude and satisfaction is a distinction between service quality and satisfaction; perceived service 
quality is a global judgment, or attitude relating to the superiority of the service, whereas satisfaction is related to a specific transaction (Parasuraman et al., 1988). For example, customers can be satisfied with a particular service but may not feel the service firm was of high quality. Satisfaction soon decays into one's overall attitude toward purchasing products (Oliver, 1981). A second issue of speculation in the SERVQUAL model is the use of terms "importance" or "expectation" regarding the measurement and of what a visitor expects from an experience (Burns, Graefe, \& Absher, 2003). The SERVQUAL model consisted of five service quality dimensions (tangibles, reliability, responsiveness, assurance and empathy) and has been used to assess consumer expectations and perceptions of service quality for a wide range of service and retailing organizations. The five dimensions of service quality within SERVQUAL are expressed in the following manner:

Tangibles: Physical facilities, equipment and appearance of personnel Reliability: Ability to perform the promised service dependably and accurately Responsiveness: Willingness to help customers and provide prompt service Assurance: Knowledge and courtesy of employees and their ability to inspire trust and confidence

Empathy: Caring, individualized attention the organization provides its customers MacKay and Crompton $(1988,1990)$ adapted the SERVQUAL model to measure satisfaction in outdoor recreation studies. This derivation of SERVQUAL was labeled the RECQUAL model of customer satisfaction, and determined only four of the five attributes were applicable to recreation settings (tangibles, reliability, responsiveness and assurance). The authors indicated that in determining satisfaction, the measurement of expectations and perceptions was not adequate, and that the significance of individual attributes was as important. Absher, Howart, Crilley, and Milne (1996) and Howart, Absher, Crilley, and Milne (1996) further designed a 
model focusing on recreation for indoor and outdoor services that included four domains (facilities sufficiency, facilities operations, services, information). Burns (2000) and Burns et al. (2003) later developed a recreational services model using an expanded four domain model (facilities, services, information, and recreation experience). The SERVQUAL, RECQUAL, Absher et al. and Burns et al. models focused on market segmentation utilizing the "gaps model." The model strived to explain the gap between expected service and perceived service. A critique of the gap method, Babakus and Boller (1992) and Carman (1990) suggested the expectation score was not necessary in determining satisfaction levels (Burns, 2003). Relying on the use of focus groups, Absher, et al. (1996) and Howat, et al. (1996) developed a model of service performance through the use of three domains (facilities, service, and information). Further analysis of their work included a fourth domain that emerged from the facilities domain that included facilities sufficiency and facility operations (Burns, et al., 1997).

For this study at two separate university recreation centers, the three dimension model of facilities, services and information based on Absher, et al. (1996) was utilized. This model includes 15 satisfaction items across the three dimensions. The domains and attributes characterize areas of recreation that management can influence to create a quality recreation environment. Each domain includes an overall measurement of satisfaction, and an additional overall measure of quality of experience was calculated.

Student recreation centers have become a standard facility on campuses across the country. Accordingly, it is no longer sufficient to measure the success of the center based on usage numbers and satisfaction with programming and staff. Many studies have shown that students expect more from their college experience outside of the classroom including recreation facilities, wellness, social events and activities (Dalgarn, 2001; Haines, 2001; Nesbitt, 1993; 
Tsigilis, Masmanidis \& Koustelios, 2009). University administrators nationwide have come to recognize the pivotal role played by recreation in college life, and often strive to improve the quality of student recreation experiences in an effort to achieve higher overall user satisfaction (Osman, Cole \& Vessell, 2006).

Service quality and satisfaction has been studied within sport, leisure and campus recreation (Absher et al.; 1996; Ko \& Pastore, 2004, 2005, 2007; MacKay et al., 1988; Osman et al., 2006; Shonk, Carr \& De Michele, 2010). MacKay and Crompton (1988) defined recreation service quality as the outcome of a comparison between expectations of a service and what is perceived to be received. The model of perceived recreation service quality was adapted from the Parasuraman et al. (1985) five dimension model and applied to the field of outdoor recreation.

Absher et al. (1996) created CSQ (Customer Service Quality) for sport and leisure centers in Australia and New Zealand. This model had similar attributes to SERVQUAL, however was tailored to focus on specific program elements and on delivering services effectively to customers. The CSQ addressed factors that influenced customer expectations in separate segments of the leisure industry, as well as site-specific customer feedback at fourteen different leisure centers.

Ko and Pastore (2004) studied current issues of service quality and proposed a four dimension model in the sport industry. This model consisted of: program quality (activity classes), interaction quality (how the service is delivered), outcome quality (what the consumer gained from the service) and physical environment quality (built environment as opposed to natural environment) and a section of customer satisfaction to be empirically tested in the field. Ko and Pastore (2007) presented the instrument Scale of Service Quality in Recreational Sports 
(SSQRS) to campus recreation programs to determine service quality and customer satisfaction in recreational sport programs. By utilizing SSQRS, campus recreation programs can improve their offerings and retain current participants, and an improved service delivery may increase quality perceptions and their level of satisfaction (Ko \& Pastore, 2007). Osman, et al. (2006) developed a questionnaire for students at a campus recreation center based on student user opinions of facility ambiance, operations quality, staff competency, satisfaction with services and future intentions to re-use the center. The results supported previous findings that higher service quality leads to higher user satisfaction and that the three dimensions were predictors of user satisfaction.

Shonk et al. (2010) used a modified version of Ko and Pastore's (2007) Scale of Service Quality in Recreational Sports (SSQRS) assessing service quality factors for 4000 campus faculty and undergraduate student recreational users at a university setting. The questionnaire investigated the dimensions of Program Quality, Interaction Quality, Outcome Quality and Physical Environment Quality, Satisfaction and Identification to determine if Identification moderated the relationship between the service dimensions and satisfaction. Shonk determined that higher Identification related to higher Satisfaction and also had a significant interactive effect when added to Outcome Quality which included physical change, sociability and valence.

Service quality is based upon characteristics of services and how they are delivered. The current model, replicated from Burns (2000) includes the domains of facilities, services and information. The Burns et al. (2003) Recreation Experience domain was removed, as the attributes of the Recreation Experience domain were directed specifically toward customers in outdoor recreation settings. The attributes of the facilities, services and information domains were applicable to the two separate university recreation center settings that were evaluated in 
this study.

\section{Project Background}

University A (UA) is a NCAA Division I, land grant university located in a small town of 28,600. The university's population of 29,000 students doubles the size of the community. The university population ratio is $52 \%$ male and $48 \%$ female and 5,500 live in on-campus residence halls. A campus referendum took place April, 1997 with $72 \%$ of the participating students voting in favor of assessing a special fee to allow for planning of a new student center. Construction on the Student Recreation Center (SRC) began in October 1999, and the Student Recreation Center was completed in July 2001. The new 177,000 square foot, $\$ 34$ million dollar recreation center is centrally located on 12 acres on the campus and is heavily used by many students. The SRC is located in close proximity to a large residential complex consisting of 2,500 freshmen students, with the intent of encouraging new student involvement and utilization of the facility.

University B (UB), a NCAA Division II university, is also situated in a small town of 19,000 people, located about 15 miles from UA. The university has a population of 7,450 students, with 840 (nine percent) living in residence halls. The university population ratio is $57 \%$ female and $43 \%$ male. A student referendum vote was conducted and $82 \%$ of the student population voted to approve the additional assessment of student fees to support the construction of a new facility. The UB student facility opened January 2005 and has also been extensively used since its opening. The UB student facility is unique in that both a student recreation center and student union are housed in a 145,000 square foot facility. The facility, centrally located on campus, includes recreation and fitness areas, dining services, conference area, computer labs, student health services, copy center, and campus security. 


\section{Methodology}

A pilot study was administered at University B's Student Activity Center (SAC) in October, 2007, with a total of 68 pilot surveys returned and analyzed. The pilot study revealed specific questions with complex tables that were frequently left unanswered. For this reason the final survey instrument was simplified and edited, allowing for more thorough completion of tables and questions.

The final survey was administered in October, 2008 at both University A and University B. Surveys were collected at both institutions on three different days and times to ensure the sample included as diverse a group of respondents as possible. At both centers, tables were located in a central location adjacent to the primary ingress and egress points. Respondents were notified that the results of the study would be part of an academic effort and that the benefits of the study would be used to help improve recreation opportunities at the university. On average, each survey took approximately 10 minutes to complete. A total of 553 surveys were collected, with 285 collected from UA and 268 surveys from UB. No personal information was collected that could link the student's identification to a completed survey. Participants were given a free non-alcoholic drink for completing the questionnaire to encourage participation. The questionnaire queried participants about their satisfaction associated with various facets of their recreation experience. This included facilities management, service provided by staff, and a series of facility satisfaction measures.

To understand differences, if any, between the UA and UB students, the respondents were asked a series of questions about their socio-demographic makeup and student status, such as on/off campus, years in college, and so forth.

Participants were queried about their overall satisfaction from utilizing their college recreation center and about their perceptions of the facility, information and service indicators. 
The following research questions were addressed:

RQ1: What is the difference in socio-demographic makeup of respondents between the two universities?

RQ2: Are there significant differences in the mean item and domain scores between the two universities?

RQ3: How well do the items and domains predict overall satisfaction within the two universities?

\section{Instrumentation}

After reviewing several different previously administered survey instruments, this study's instrument was extended using questions from two existing questionnaires (Burns, Graefe \& Absher, 1997; Lawson, 2008). After selecting several imperative questions from the existing surveys, additional questions were designed and directed toward usage, satisfaction, health and demographics of the student population at university settings.

This manuscript focuses on the results pertaining to satisfaction within the domains of facilities, services and information. A series of questions were asked utilizing a Likert scale ranging from 1 (Very Unsatisfied) to 5 (Very Satisfied). Facility domain questions included convenience of the location, appearance and maintenance of the area, lighting, bathroom and locker rooms, exercise equipment, multi-purpose courts and fitness rooms. Service domain questions included visibility of staff, safety and security of the area, courteous and friendly staff, opportunity to offer suggestions to staff, hours of the facility, and available programs. Information domain questions included ease of obtaining information and if current and accurate information about activities in the building were available. The satisfaction domains were modeled from previous studies focused on facilities, services and information as defined by Absher et al. (1996) and Howat et al. (1996). The final satisfaction measure was a measure of overall quality of experience on a typical visit to the recreation center, derived from Burns 
(2000).

A series of multiple regression tests were utilized to determine the relationships between satisfaction ratings and individual scores. The dependent variables included measures of both overall and domain specific satisfaction, while the independent variables were measures of satisfaction of individual attributes within each domain. The conceptual model is presented in Figure 1. Regression analysis was used to express the predictive power of the hypotheses. In addition, two separate analyses were conducted to understand the differences in the satisfaction models between the two universities.

-Insert Figure 1 about here

\section{Results}

RQ1: What is the difference in socio-demographic makeup of respondents between the two universities?

Overall, male students (56.6\%) made up a majority of the respondents (Table 1$)$. UA respondents were more likely to be male $(65.9 \%)$, while UB were slightly more likely to be female $(53.4 \%)$. The vast majority of respondents $(90.3 \%)$ were White, full-time students $(97.8 \%)$ enrolled in 12 or more credit hours. Just over half of the respondents $(52.7 \%)$ did not work and almost half (47.3\%) lived in off campus housing.

-Insert Table 1 about here

The vast majority of all students who participated in this study were White. Significant differences regarding race were noted between the students at UA and UB, with UB students being significantly more diverse than UA students. Only a small proportion of UA students $(5.4 \%)$ reported their racial background as non-White, compared to $14.1 \%$ at UB. University B was about four times as likely to include Asian students (7.6\%) than UA (1.8\%). Also, the UB student population included twice as many Black students (9.2\%), as compared to UA (4.3\%). 
There was no significant difference in the Hispanic population between the universities.

Enrollment status was similar between the universities, with UA having 98.9\% full time and $1.1 \%$ part time students, and UB having $96.6 \%$ full time and 3.4\% part time students. Employment status between the universities was significantly different, with $57.3 \%$ of UA reporting they did not work, $35.1 \%$ reported working part time and $7.5 \%$ reported working full time. UB was somewhat different, with $47.7 \%$ not working, $38.2 \%$ working part time and $14.1 \%$ working full time.

Overall, one third of the respondents $(33.1 \%)$ were first year students, $21.6 \%$ second year students, $18.5 \%$ third year students, and $26.8 \%$ were in their fourth or higher year. The results were significantly different between students at the two universities, with about half (49.6\%) of UA students being in their first or second years, compared to $60.3 \%$ of UB students being in their first or second year.

RQ2: Are there significant differences in the mean item and domain scores between the two universities.

To evaluate the differences in mean item and domain scores, participants rated their overall experiences using a Likert scale ranging from 1 (Not at all Satisfied) to 5 (Extremely Satisfied). A comparison of means scores using an independent t-test was conducted to determine if there were significant differences between the two universities.

To analyze the predictive power of the domains (facilities, services, information) on overall satisfaction, a regression model was developed. Each of these variables was presented on the survey instrument as a separate question about the visitor's overall quality of each of the three domains also utilizing a Likert scale ranging from 1 (Not at all Satisfied) to 5 (Extremely Satisfied).

1. How would you rate the overall quality of Facilities at the center? 
2. How would you rate the overall quality of Services at the center?

3. How would you rate the overall quality of Information at the center?

Results showed the highest mean values of satisfaction for UA were multi-purpose courts (mean=4.47), in the Facilities domain, hours of facility (mean=4.45), in the Services domain and lastly current and accurate information about activities in the building (mean=4.25), in the Information domain. For UB, convenient location (mean $=4.40$ ), in the Facilities domain, safety and security of the area $($ mean=4.16), in the Services domain, and current and accurate information about activities in the building (mean=4.09), in the Information domain rated the highest mean scores. The highest overall mean for domains was Facilities (mean=4.41).

When comparing the two facilities, the results showed that three of the Facilities domain items were significantly different. These included convenient location (UA mean=3.94, UB mean $=4.40, \mathrm{p}<.001$ ), lighting (UA mean $=4.41, \mathrm{UB}$ mean $=4.15, \mathrm{p}<.01)$ and multi-purpose court (UA mean $=4.47$, UB mean $=4.32, \mathrm{p}<.01$ ). Within the Services domain, two items were both significant at $\mathrm{p}<.01$; this included visibility of staff $(\mathrm{UA}$ mean=4.04, UB mean=3.88) and hours of facility (UA mean $=4.45$, UB mean=3.80). There were no items that measured significant in the Information domain.

-Insert Table 2 about here-

Differences in ratings were evaluated for the three domains (facilities, services and information) across the two universities. University A students reported significantly higher ratings for all three domains. The facilities domain showed the highest overall mean (UA Mean $=4.41$, UB mean=4.15, $\mathrm{p}<.001)$, followed by the services domain $(\mathrm{UA}=4.19, \mathrm{UB}=4.01$, $<.05)$ and information domain $(\mathrm{UA}=4.04, \mathrm{UB}=3.83, \mathrm{p}<.01)$. Using a scale of $1-10$ on rating your overall quality of experience for a typical visit, while similarly high at both universities, 
was also significantly different $(\mathrm{UA}=8.56, \mathrm{UB}=8.22, \mathrm{p}<.05)$.

-Insert Table 3 about here

RQ3: How well do the items and domains predict overall satisfaction within the two universities?

A series of multiple regression tests were used to examine the two satisfaction models within the two universities. First, the individual items within the three domains (facilities, services and information) were regressed against their respective domains. The three dependent variables (the domains) then became three independent variables, and the strength of these domains on the ultimate dependent variable of overall satisfaction was measured. A final question regarding the overall quality of experience was asked as follows:

On a scale of 1-10, how would you rate your overall quality of experience of the center for a typical visit?

\section{$\underline{\text { University A }}$}

Just one of seven facilities items was a significant predictor of domain satisfaction (appearance and maintenance of area, Beta=.258), accounting for about $21 \%$ of the variance associated with overall satisfaction within the facility domain (Figure 2). Similarly, just one of the six services items was a significant predictor of satisfaction within the services domain (courteous and friendly staff) Beta=.434, accounting for $29 \%$ of the variance in satisfaction within the services domain. Lastly both of the information items (ease of obtaining information, Beta $=.398$ and current and accurate information about activities in the building, Beta=.205) were significant predictors, accounting for $28 \%$ variance in satisfaction within information domain.

The UA customer satisfaction model accounted for about $34 \%$ of variance in the overall quality of experience. Quality of facilities domain (Beta = .279), Quality of services domain 
(Beta=.279) and Quality of information domain (Beta=.128) accounted for the overall satisfaction experience.

Insert Figure 2 about here

\section{$\underline{\text { University } B}$}

Two of seven facilities items were significant predictors of domain satisfaction (appearance and maintenance of area, Beta=.215) and (bathrooms/locker rooms, Beta=.186) accounting for about $20 \%$ of the variance associated with overall satisfaction within the facility domain (Figure 3). Similarly, two of the six services items were significant predictors of satisfaction within the services domain (visibility of staff, Beta=.217) and (courteous and friendly staff, Beta=.193), accounting for $39 \%$ of the variance in satisfaction within the services domain. Lastly both of the information items (ease of obtaining information, Beta=.261 and current and accurate information about activities in the building, Beta=.321) were significant predictors, accounting for $26 \%$ variance in satisfaction within information domain.

The UB customer satisfaction model accounted for about $57 \%$ of variance in the overall quality of experience. The Quality of facilities domain (Beta=.347), Quality of services domain (Beta=.341) and Quality of information domain (Beta=.154) accounted for the overall satisfaction experience.

-Insert Figure 3 about here

The UB model proved to be a stronger predictor of overall satisfaction than the model tested at UA. The overall amount of variance in satisfaction with the overall quality of experience accounted for at University B was 57\%, compared to just $34 \%$ at University A. Quality of facilities and services were equal predictors for UA and quality of facilities was the strongest predictor for UB. Overall Quality of facilities was the strongest predictor of overall satisfaction. 


\section{Conclusions}

The purpose of this study was to examine customer satisfaction at two separate university recreation centers and to explore service quality indicators as predictors of customer satisfaction utilizing a model to examine relationships. A review of customer satisfaction models facilitated the decision to replicate the Burns et al. (2003) and Absher et al. (1996) models utilizing facilities, services and information domains and attributes to measure satisfaction and overall quality of experience. This study builds on previous recreational customer satisfaction research in an attempt to measure and predict overall satisfaction in college student recreation center environments.

\section{Hypothesis Testing}

Participants at separate and unique universities were queried about their perceptions of the facility, information and service indicators and their overall satisfaction from utilizing their college recreation center.

The following research questions were analyzed:

RQ1: What is the difference in socio-demographic makeup of respondents between the two universities?

Research question one examined the differences in socio-demographic items between the two settings. UA and UB are vastly different universities in size and character, yet located only 30 miles apart. Significant differences were noted for nearly all of the social demographics at the two universities. UA respondents were predominately White, and were much more likely to be male, UB students were more likely to be part time students, more likely to be employed, and more likely to be first or second year students. UB students were also much more likely to live in a dormitory or at home, while UA students were much more likely to live in off-campus housing. These findings show the depth and breadth of the differences in the socio-demographic 
makeup of the students who utilize the two facilities.

RQ2: Are there significant differences in the mean item and domain scores between the two universities?

Research question two tested the significant differences in the mean item and domain scores between the two universities. In the Facilities domain, UA had the highest mean value for multi-purpose courts and UB had the highest value for convenient location. UA has a large student population of 29,000 with a variety of recreational needs, the recreation center was built to provide seven different multi-purpose courts to accommodate basketball, volleyball, badminton, and fitness classes; in addition three courts for racquetball and squash were also built. The patrons feel their needs are met, indicating why a high satisfaction with multi-purpose courts would occur. UB, a multi-purpose building encompassing both a student recreation center and student union is located centrally on campus. The addition of the facility to campus encourages students to eat, relax, socialize, study and recreate all in one facility. The centralized and convenient location which is popular for gathering on campus suggests why a high level satisfaction was measured. In the Services domain, UA had the highest mean value for hours of facility and UB for safety and security of the area. The university recreation center at UA is located on a northern campus close to a large residential complex and is currently open extended hours, until midnight in the evening and weekends. The large university population and management determined a need for longer facility hours to provide recreation to many students who commute and live on campus. This decision proved to be important and was indicated with a high level of satisfaction. UB measured a strong satisfaction level with the safety and security of the area. The facility is used for many purposes, such as late night studying, eating and special events, the campus security office is also located in the building and students are confident with their safety and security. For both UA and UB, current and accurate information about 
activities in the building, measured the highest mean values of satisfaction. Regardless of the size of an institution, being informed of activities and up-to-date information regarding the recreation facilities was important and measured higher satisfaction scores for both students at their perspective institutions. Research by Osman, Cole, Vessell (2006) indicated that staff competency, which includes the staff's ability to provide current information, rated the highest mean and operations quality rated the lowest mean scores. Research by Ko and Pastore (2007) utilizing the SSQRS indicated lower mean scores for operating time and information delivery system and high scores for client-employee interaction (job knowledge, competency) and interclient interaction (customer's impression of service) indicating a good attitude toward customers and expertise in their jobs equated to higher satisfaction.

When comparing the two university facilities, the Facilities domain had three significantly different items, convenient location, lighting, and multi-purpose courts. The t-test shows that a relationship exists between the two universities for these variables and measures of difference were significant. Both student populations value the location of the facility as well as the accommodations of lighting and multi-purpose courts. In the Services domain, two items (visibility of staff and hours of facility) were significantly different. Again, the freedom to utilize the recreation facilities for extended hours differed between the two campuses. Visibility of staff is an important quality in a recreation facility as safety, knowledgeable employees and customer service is central to the overall feelings of satisfaction for patrons. There were no significant items in the Information domain. Absher, et al. (1996) and the CSQ model found clear and accurate information, well and maintained facilities and organized and knowledgeable staff with significant t-test results to be important domains to test for customer satisfaction.

A comparison of the three domains (facilities, information and services) showed that 
each was significantly different between the two university facilities. As noted previously, both student populations appreciate their facility, the services offered, and the accurate information provided. A question measuring the overall quality of experience of the recreation center on a typical visit (scale of 1-10), showed high mean values for both universities. University A was rated slightly higher $($ mean $=8.56)$ when compared to University B $($ mean=8.22). This single item indicator illustrates a high level of student customer satisfaction at both campus facilities. RQ3: How well do the items and domains predict overall satisfaction within the two universities?

Research question three was addressed to determine how the items and domains predicted overall satisfaction within the two universities. Multiple regression tests examined satisfaction within the two separate universities. Individual items within the three domains were regressed against the domains and then the domains were regressed against overall satisfaction.

The regression model at UB accounted for about $57 \%$ of the variance associated with overall satisfaction, while UA's regression model explained about $34 \%$ of variance. Each domain partially supported the hypothesis by proving to be significant within each model of overall satisfaction. Individual variables within each domain were valid predictors of domain satisfaction. UA showed four variables across three domains as predictors of domain satisfaction and UB regression model showed six variables across the three domains as predictors. Appearance/maintenance of area was a predictor for both the UA and UB model, emphasizing the importance of cleanliness, working equipment and overall appearance to overall satisfaction within the Facilities domain. Similarly courteous and friendly staff was also a predictor for both universities within the Services domain. Customer service, which entails friendly and courteous staff, was a significant predictor of overall satisfaction. For both universities, the ease of obtaining information and current/accurate information about activities in building were 
predictors of overall satisfaction with information. Student populations desire to easily obtain information and insist on current, accurate and up-to-date information. Websites and social media (e.g., Facebook, Twitter, etc.) have become standard in communication, and it is critical that managers of student recreation facilities utilize these tools. The regression model focusing on the quality domains showed Quality of Facilities and Quality of Services to be stronger and equal predictors to overall satisfaction for both UA and UB.

The differences in the results of the regression models between the two universities may be a function of the distinct differences in the structure of their recreation centers. The UA facility is a student recreation center only, while UB's recreation center is combined with the university student union. The UB regression models revealed higher beta levels for both quality of Facilities and Services and similar levels for quality of Information, when compared to UA. UB is used extensively as a student union and recreation center, is considered the hub of the campus, and is also used for student gatherings and social events. The quality of this facility and its services is important to the student body as it is the only student center available to them on campus for both socialization and recreation. UA's facility is used strictly as a recreation center, and a separate student union is available for dining and social events. The UA recreation center is also an older facility than that seen on the UB campus, suggesting that students may have lower levels of expectations and lower levels of satisfaction of their overall experience. This is supported by research suggesting it is important for campus recreation staff to know their customer's needs and level of satisfaction (Shonk, et al., 2010).

\section{$\underline{\text { Research Summary }}$}

An important finding in this study is that recreational customer satisfaction continues to be challenging to measure and theorize. Customer satisfaction has been studied across many 
areas of service; marketing, tourism, business, retail, recreation management, etc., and has a variety of meanings to different people and entities. This study explored customer satisfaction at two separate college recreation centers to determine a relationship between selected facility, service and information attributes and domains within the model. In the field of recreation, various satisfaction models have been tested; RECQUAL, CSQ, SSQRS, Absher, et al., and Burns et al. This study replicated and scaled down Absher, et al. and Burns et al. models utilizing a series items and domains to determine the predictability of patron satisfaction with their facility. Prior to the construction of student recreation centers, students were surveyed to determine their wishes and requests for various amenities in the new facility. It is advantageous that administrators conduct a follow-up study to understand customer satisfaction of their students and patrons toward these new facilities, and also include measures of quality of services and information. The purpose of this research was to test a model, examine the relationships between facility, service and information attributes and predict overall satisfaction based on 15 variables and three domains. Similar to historical studies that researched and measured levels of satisfaction within various recreational environments, it is apparent that further research or further analysis is needed to better explain differences and variance in the university recreation setting. 
Table 1: Socio-demographic Characteristics

\begin{tabular}{|c|c|c|c|c|}
\hline Characteristics & UA & UB & Overall & Test Statistic \\
\hline \multicolumn{5}{|l|}{ Gender $\%$} \\
\hline Male & 65.9 & 46.6 & 56.6 & \\
\hline Female & 34.1 & 53.4 & 43.4 & $\chi^{2}=20.66 * * *$ \\
\hline \multicolumn{5}{|l|}{ Ethnicity \% } \\
\hline White & 94.3 & 85.9 & 90.3 & $\chi^{2}=11.02 * * *$ \\
\hline Black & 4.3 & 9.2 & 6.6 & $\chi^{2}=5.29 * *$ \\
\hline Asian & 1.8 & 7.6 & 4.6 & $\chi^{2}=10.64 * * *$ \\
\hline Hispanic & 13.2 & 15.0 & 14.0 & \\
\hline \multicolumn{5}{|l|}{ Enrollment Status \% } \\
\hline Full time (12+ credits) & 98.9 & 96.6 & 97.8 & \\
\hline Part time ( $<12$ credits) & 1.1 & 3.4 & 2.2 & $\chi^{2}=3.37$ \\
\hline \multicolumn{5}{|l|}{ Years in College \% } \\
\hline $1^{\text {st }}$ year & 25.2 & 41.8 & 33.1 & \\
\hline $2^{\text {nd }}$ year & 24.4 & 18.5 & 21.6 & $\chi^{2}=16.57^{* * *}$ \\
\hline $3^{\text {rd }}$ year & 19.6 & 17.3 & 18.5 & \\
\hline $4^{\text {th }}$ year and higher & 30.7 & 22.5 & 26.8 & \\
\hline \multicolumn{5}{|l|}{ Employment Status \% } \\
\hline Works full time & 7.5 & 14.1 & 10.7 & \\
\hline Works part time & 35.1 & 38.2 & 36.6 & $\chi^{2}=8.21 *$ \\
\hline Does not work & 57.3 & 47.7 & 52.7 & \\
\hline \multicolumn{5}{|l|}{ Living while in School \% } \\
\hline Dorms/campus apartments & 23.6 & 43.7 & 33.3 & \\
\hline Off campus housing & 68.6 & 24.5 & 47.3 & $\chi^{2}=1.12 * * *$ \\
\hline Home & 7.9 & 31.8 & 19.4 & \\
\hline
\end{tabular}

Note. ${ }^{*} \mathrm{p}<.05,{ }^{* *} \mathrm{p}<.01,{ }^{*} * * \mathrm{p}<.001$. 
Table 2: Comparison of Mean Values for 15 items within Domains and Domain Values

\begin{tabular}{|l|l|l|l|l|}
\hline FACILITIES & $\begin{array}{l}\text { Mean } \\
\text { UA }\end{array}$ & $\begin{array}{l}\text { Mean } \\
\text { UB }\end{array}$ & $\begin{array}{l}\text { Mean } \\
\text { Overall }\end{array}$ & F-Value \\
\hline Convenient location & 3.94 & 4.40 & 4.17 & $10.292^{* * *}$ \\
\hline Appearance/ maintenance of area & 4.39 & 4.29 & 4.34 & \\
\hline Lighting & 4.41 & 4.15 & 4.28 & $7.990^{* *}$ \\
\hline Bathrooms/locker rooms & 4.26 & 4.23 & 4.25 & \\
\hline Exercise equipment & 4.29 & 4.31 & 4.30 & \\
\hline Multi-purpose courts & 4.47 & 4.32 & 4.40 & $7.122^{* *}$ \\
\hline Fitness rooms & 4.29 & 4.28 & 4.28 & \\
\hline SERVICES & & & & \\
\hline Visibility of staff & & & $3.025^{* *}$ \\
\hline Safety and security of the area & 4.04 & 3.88 & 3.96 & \\
\hline Courteous and friendly staff & 4.32 & 4.16 & 4.24 & \\
\hline Opportunity to offer suggestions to staff & 4.22 & 4.14 & 4.18 & \\
\hline Hours of facility & 4.45 & 3.59 & 3.60 & \\
\hline Available Programs & 4.23 & 3.99 & 4.12 & \\
\hline & & & & \\
\hline INFORMATION & & & & \\
\hline Ease of obtaining information & 4.09 & 3.98 & 4.04 & \\
\hline $\begin{array}{l}\text { Current and accurate information about } \\
\text { activities in the building }\end{array}$ & 4.25 & 4.09 & 4.17 & \\
\hline Note. Scale: & & & & \\
\hline S & & & & \\
\hline
\end{tabular}

Note. Scale: $1=$ Not at all satisfied to $5=$ Extremely satisfied

Note. $* * \mathrm{p}<.01, * * * \mathrm{p}<.001$. 
Table 3: Domain and Overall Satisfaction Mean

\section{Quality of Domain Satisfaction}

\begin{tabular}{|l|c|c|c|l|}
\hline DOMAIN & $\begin{array}{c}\text { UA } \\
\text { MEAN }\end{array}$ & $\begin{array}{c}\text { UB } \\
\text { Mean }\end{array}$ & Overall Mean & F-Value \\
\hline Facilities & 4.41 & 4.15 & 4.28 & $18.053^{* * *}$ \\
\hline Services & 4.19 & 4.01 & 4.10 & $6.392^{*}$ \\
\hline Information & 4.04 & 3.83 & 3.93 & $7.145^{* *}$ \\
\hline
\end{tabular}

Note. Scale: $1=$ Not at all satisfied to $5=$ Extremely satisfied Note. $* \mathrm{p}<.05, * * \mathrm{p}<.01, * * * \mathrm{p}<.001$.

On a scale of 1-10, how would you rate your overall quality of experience of the center for a typical visit?

\begin{tabular}{|l|l|l|l|}
\hline UA Mean & UB Mean & Overall Mean & F-Value \\
\hline 8.56 & 8.22 & 8.39 & $12.365^{*}$ \\
\hline
\end{tabular}

Note. Scale: $1=$ Not at all satisfied to $10=$ Extremely satisfied

Note. ${ }^{*} \mathrm{p}<.05$ 
Figure 1: Conceptual Model of Customer Satisfaction

\section{Conceptual Model of Customer Satisfaction}

\section{Satisfaction with Items \\ Quality of Domains \\ Overall Satisfaction}

Convenient location

Appearance/ maintenance of area

Lighting

Bathrooms/locker rooms

Exercise equipment

Multi-purpose courts

Fitness rooms

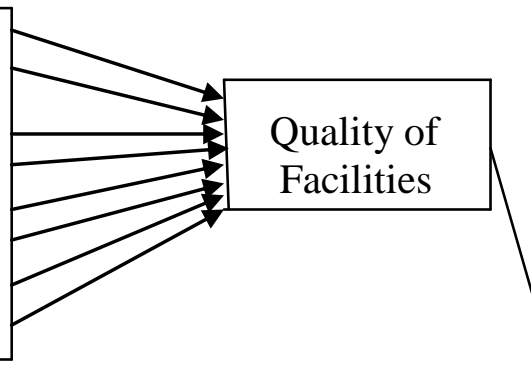

Visibility of staff

Safety/security of the area

Courteous and friendly staff

Opportunity to offer suggestions to staff

Hours of facility

Available Programs

Ease of obtaining information

Current /accurate information about activities in the building 
Figure 2: Customer Satisfaction Model - University A

\section{Customer Satisfaction Model: University A}

\section{\begin{tabular}{|l|l|l|}
\hline Satisfaction with Items & Quality of Domains \\
\hline
\end{tabular}}

Convenient location
Appearance/ maintenance of area
Lighting
Bathrooms/locker rooms
Exercise equipment
Multi-purpose courts
Fitness rooms

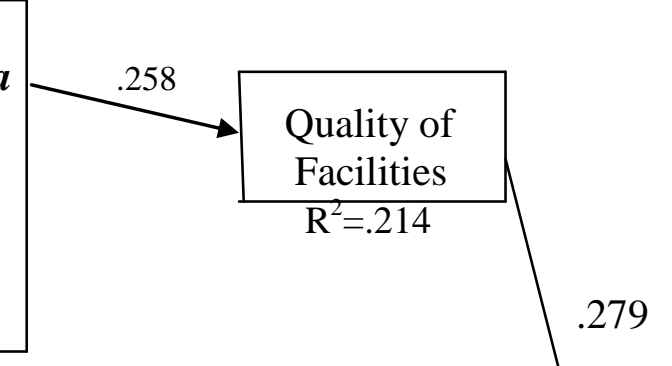

Visibility of staff

Safety/security of the area

Courteous and friendly staff

Opportunity for staff suggestions

Hours of facility

Available Programs

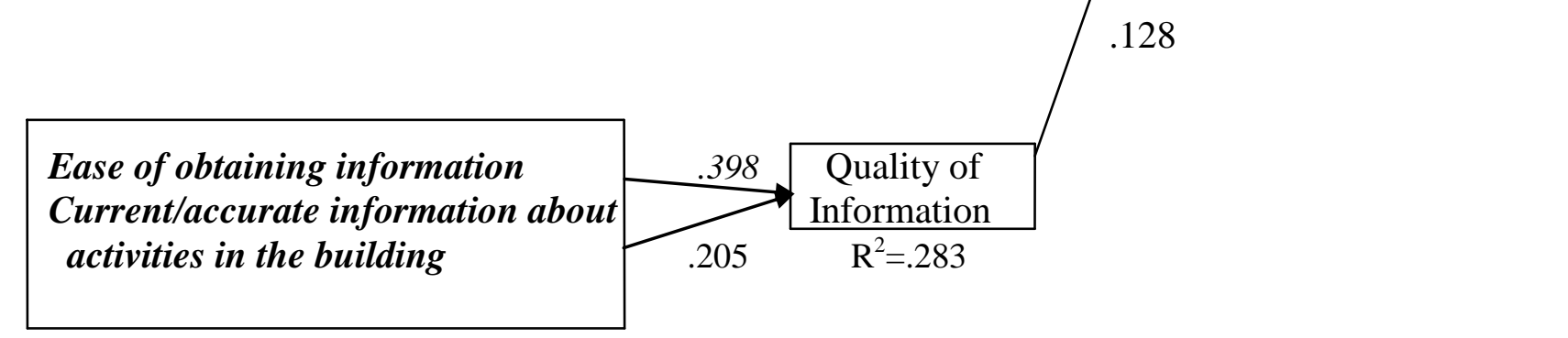


Figure 3: Customer Satisfaction Model - University B

\section{Customer Satisfaction Model: University B}

\section{Satisfaction with Items \\ Quality of Domains \\ Overall Satisfaction}

Convenient location

Appearance/ maintenance of area

Lighting

Bathrooms/locker rooms

Exercise equipment

Multi-purpose courts

Fitness rooms

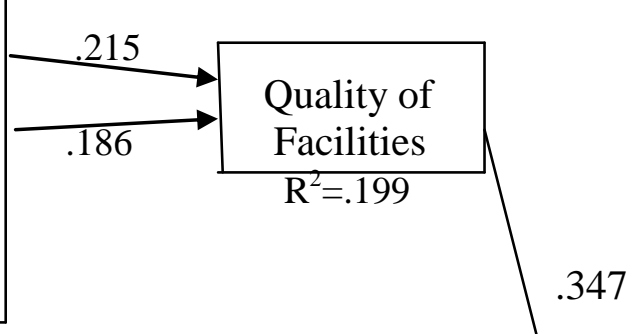

347

\section{Visibility of staff}

Safety/security of the area

Courteous and friendly staff

Opportunity for staff suggestions

Hours of facility

Available Programs

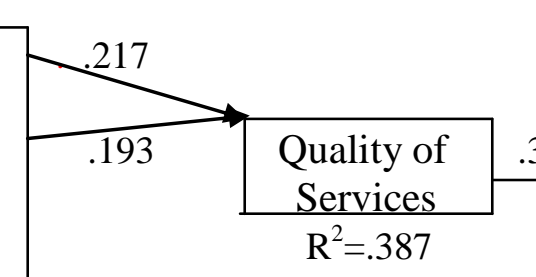

$\mathrm{R}^{2}=.387$
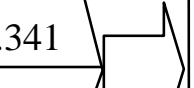

Satisfaction with Overall Experience

\section{Ease of obtaining information Current /accurate information about activities in the building}

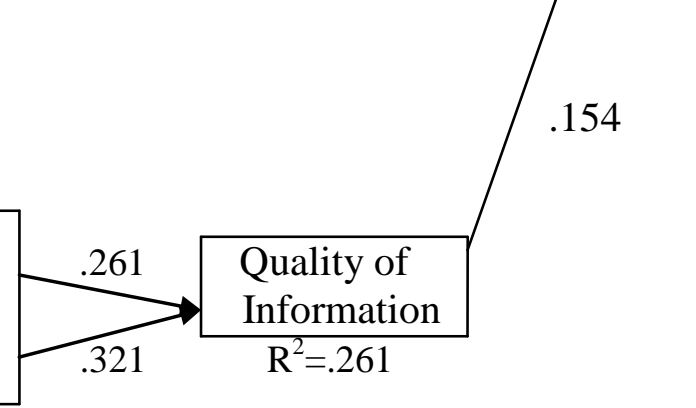

$$
\mathrm{R}^{2}=.566
$$




\section{References}

Absher, J., Howart, G., Crilley, G., \& Milne, I. (1996). Toward quality customer service: Market segment differences for sports and leisure centres. Australian Leisure, 7(1), 24-28.

Babakus, E. \& Boller, G.W. (1992). An empirical assessment of the SERVQUAL scale. Journal of Business Research, 24, 253-268.

Burns, R.C., Graefe,. A.R \& Absher, J. (1997). A literature review of customer satisfaction and service quality theories and methods for resource-based recreation. Report prepared under cooperative agreement PSW-97-0016CA, Pacific Southwest Research Station, USDA Forest Service, Riverside, California.

Burns, R.C. (2000). Methodological issues associated with customer satisfaction measurement and market segmentation at water-based recreation areas (Doctoral dissertation). Retrieved from http://etda.libraries.psu/edu.

Burns, R.C., Graefe, A.R., \& Absher, J. (2003). Alternate measurement approaches to recreational customer satisfaction: Satisfaction-only versus gap scores. Leisure Sciences, 25, 363-380.

Carman, J.M. (1990). Consumer perceptions of service quality: An assessment of the SERVQUAL dimensions. Journal of Retailing, 66, 33-55.

Dalgarn, M.K. (2001). The role of the campus recreation center in creating a community. NIRSA Journal, 25(1), 66-72.

Haines, D.J. (2001). Undergraduate student benefits from university recreation. Recreational Sports Journal, 25(1), 25-33.

Howart, G., Absher, J., Crilley, G., \& Milne, I. (1996). Measuring customer service quality in sports and leisure services. Managing Leisure, 1, 77-89.

Ko, Y.J. \& Pastore, D.L. (2004). Current issues and conceptualizations of service quality in the recreation sport industry. Sport Marketing Quarterly, 13, 158-166.

Ko, Y.J. \& Pastore, D.L. (2005). A hierarchical model of service quality for the recreational sport industry. Sport Marketing Quarterly, 14, 84-97.

Ko, Y.J. \& Pastore, D.L. (2007). An instrument to assess customer perceptions of service quality and satisfaction in campus recreation programs. Recreational Sports Journal, 31(1), 3442. 
Lawson, L. (2008). Using social support and theoretically derived messages to increase awareness and use of the C\&O Canal National Historical park for walking: An intervention focused on local employees. Unpublished Master's Thesis. West Virginia University, Morgantown, W.V.

MacKay, K.J. \& Crompton, J.L. (1988). A conceptual model of consumer evaluation of recreation service quality. Leisure Studies, 7, 41-49.

MacKay, K.J. \& Crompton, J.L. (1990). Measuring the quality of recreation services. Journal of Park and Recreation Administration, 8 (3), 47-56.

Nesbitt, G. (1993). What effect do our programs have on our participants? NIRSA Journal, 17, 16-18.

Oliver, R. (1981). Measurement and evaluation of satisfaction process in retail settings. Journal of Retailing, 57, 25-48.

Osman, R.W., Cole, S.T. \& Vessell, C.R. (2006). Examing the role of perceived service quality in predicting user satisfaction and behavioral intentions in a campus recreation setting. Recreation Sports Journal, 30 (1), 20-29.

Parasuraman, A., Zeithaml, V.A., \& Berry, L.L. (1985). A conceptual model of service quality and its implications for future research. Journal of Marketing, 49, 41-50.

Parasuraman, A., Zeithaml, V.A., \& Berry, L.L. (1988). SERVQUAL: A multiple-itm scale for measuring consumer perceptions of service quality. Journal of Retailing, 64(1), 12-40.

Shonk, D.J., Carr, J.W. \& De Michele, P.E. (2010). Service quality and satisfaction within campus recreation: The moderating role of identification. Recreational Sports Journal, 34(1), 9-23.

Tsigilis, N., Masmanidis, T., \& Koustelios, A. (2009). University students' satisfaction and effectiveness of campus recreation programs. Recreational Sports Journal, 33(1), 65-76.

Zeithaml, V.A. (1987). Defining and relating price, perceived quality, and perceived value. Report No. 87-101, Cambridge, MA: Marketing Science Institute. 


\title{
CHAPTER 4: PAPER 3
}

Similarities and Differences in Physical Activity among University Students

\begin{abstract}
Objective: This study examined demographic characteristics of college students and investigated the relationships between characteristics and physical activity patterns. Participants: In October, 2008, 553 undergraduates were surveyed at two separate recreation centers. Method: Various statistics are reported; demographics, physical activity patterns, reasons to exercise, attitudes toward physical activity and which variables would lead to the propensity to exercise vigorously. Results: The typical student was White, with $12+$ credit hours, a first or second year student who lived in off campus housing. In a typical week a student engaged in physical activity for at least 30 minutes, 3.47 times per week. Predominantly the reason to use the facility was for physical exercise. Living arrangements and using the facility for socialization/recreation were significant variables influencing activity patterns and opinions of exercise. Conclusions: Expanding on previous research, these findings are supportive of the importance of physical activity, recreation and socialization on university campuses.
\end{abstract}

Keywords: physical activity, health, recreation, socialization 
Over the past 30 years a new type of facility has emerged at colleges and universities across the United States. These buildings have been called student recreation centers, student activity centers, or centers for physical activities. ${ }^{1}$ Many universities nationwide have hired consultants to assess campus recreation needs, communicate with student focus groups and assess student values, interests and needs resulting in the building of campus recreation facilities. The clear message is that universities need to offer quality activities and facilities to enrich student life to incoming and returning students; physical activity has shown to help students develop both socially and physically. For this reason, higher education professionals have designed or remodeled facilities and campuses to promote physical activity.

The American College Health Association (ACHA), an organization dedicated to the health needs of college students has developed many survey instruments to collect information on student health behaviors. The ACHA Healthy Campus 2010 initiative identifies physical activity as one of the six priority health risk behaviors for college populations. ${ }^{2}$ Physical activity plays an important function in prevention of disease, weight control and social well being. Despite many positive outcomes, physical activity among the majority of Americans remains sedentary. The rates of inactivity among college-aged people is of great concern as research suggests being overweight and unhealthy during late adolescence is associated with an increase of being overweight and susceptible to disease in adulthood. ${ }^{3}$ Regular physical activity is also related to psychological well-being with established links to lower levels of anxiety, depression, stress and negative moods. ${ }^{4}$ Physical activity behaviors that students establish in college will have a long-term effect on adult habits. In 1995, the Centers for Disease Control and Prevention (CDC) and the American College of Sports Medicine (ACSM) issued a recommendation that every US adult should accumulate 30 minutes or more of moderate-intensity physical activity on 
most days of the week. ${ }^{5}$ More than ten years has passed since the recommendation and new science has added to the benefits of physical activity; also evidence continues that U.S. adults are still not active. The current recommendation for healthy adults aged 18-65 years are moderateintensity aerobic physical activity for at least 30 minutes, five days each week, or vigorousintensity aerobic activity for a minimum of 20 minutes on three days each week; combinations can be performed to meet this recommendation. ${ }^{6}$ Part of this recommendation includes vigorousintensity activity described as rapid breathing and increase in heart rate and moderate-intensity equivalent to a brisk walk and accelerates the heart rate.

Many federal agencies have conducted extensive research emphasizing the importance of health, physical activity and obesity in the United States. The U.S. Department of Health and Human Services (HHS), other federal agencies and public stakeholders developed the Healthy People 2020 framework under the leadership of the Federal Interagency Workgroup (FIW). The framework and overarching goals of Healthy People 2020 is to promote good health for all, attain high-quality longer lives free of preventable disease, achieve health equity and improve the health of all groups. ${ }^{7}$

The 2010 Surgeon General's vision for a healthy and fit nation stated the prevalence of obesity changed relatively little during the 1960s and 1970s, but has increased sharply over the ensuing decades $-13.4 \%$ in 1980 to $34.3 \%$ in 2008 among adults. ${ }^{8}$ Obesity is caused by consuming too many calories and not getting enough physical activity as well as genes, metabolism, behavior, environment and culture. Physical activity is important for the control of obesity and is essential for health at any weight. Furthermore, an obese teenager has a greater than $70 \%$ risk of becoming an obese adult. ${ }^{9}$ Both nutrition and physical activities among college students have been researched and indicate that physical activity frequency and eating habits 
vary among overweight and healthy weight students; healthy weight students tended to exercise and eat healthy opposed to overweight students. ${ }^{10}$ Among college students, nearly $35 \%$ are reported to be overweight. ${ }^{11}$

The American College Health Association, National College Health Assessment (ACHANCHA) developed a broad Student Health Survey in 1998 to assist institutions of higher education understand health needs to progress in creating healthy campus communities. Five questions were related to weight, nutrition and exercise. In 2003, $44.2 \%$ of students reported that they exercised vigorously for at least 20 minutes or moderately for at least 30 minutes on 3 out of 7 past days. ${ }^{12}$ The Spring 2008 reference group data report of 80,121 student participants reported $45.5 \%$ exercising vigorously for 20 minutes or moderately for 30 minutes on at least 3 of the past 7 days. ${ }^{11(\mathrm{p} 480)}$

Based on 105,781 surveys tabulated by the Spring 2011 Reference Group Data Report' several detailed physical activity trends emerged: $92.7 \%$ of students described their general health as good, very good or excellent, $35 \%$ described their weight as overweight and $52 \%$ were trying to lose weight. As for cardio exercise trends: $71 \%$ participated in cardio exercise 0-3 days per week at moderate intensity for 30 minutes, $29 \%$ participated in cardio exercise 4-7 days in a week at moderate intensity for 30 minutes, $81 \%$ did vigorous intensity cardio exercise 0-3 days per week for 20 minutes and 19\% did vigorous intensity cardio exercise 4-7 days for 20 minutes. $^{13}$

These self-reported surveys show an increase in exercise trends from college age students, yet data from the 2005 American College of Sports Medicine (ACSM) indicates that the proportion of people meeting the current exercise recommendations has declined $59.6 \%$ among the $18-24$ years of age. ${ }^{6(\mathrm{p} 1424)}$ 
In 2005, a group of authors researched and compiled a meta-analysis of college students' physical activity behaviors. The authors found problems with current studies suggesting that research on college students physical activity has been neglected, there is a lack of multiple-level approaches, and measures of physical activity (PA) are subjective and inconsistent, making a comparison among different samples difficult. ${ }^{14}$ Bray and colleagues in their analysis also concurred that there is no uniformly accepted method of measuring physical activity. ${ }^{15}$ The meta-analysis determined key factors influencing students' PA including exercise preference and participation in moderate and vigorous activity. Physical activity patterns have carryover effects into adulthood and researchers found that $84.7 \%$ of those who exercised regularly were still active physically 5-10 years later. ${ }^{14(\mathrm{p} 119)}$ Personal factors (age, gender, ethnicity, year in university, physical activity history and health status) were also researched and examined by Keating and other researchers. ${ }^{3,16,17,18}$

Additional areas of research and physical activity patterns in college age students include exercise self-efficacy, ${ }^{16}$ predictors of exercise relapse in college population, ${ }^{19}$ physical activity associated with psychological well-being, ${ }^{15}$ and theory of planned behavior in predicting physical activity with university students..$^{20}$ Certain demographic backgrounds such as gender and race indicate a trend in decline in physical activity during adolescence. ${ }^{21}$ Researchers found that $49.7 \%$ of male college students were vigorous exercisers and $12.1 \%$ were inactive compared to $30.7 \%$ of female students classified as vigorous exercisers and $12 / 1 \%$ as inactive. ${ }^{22}$ Also examined was the status of physical activity among international students attending colleges in the United States. Descriptive statistics revealed that international students spent an average of 3.4 hours in physical activity weekly. Female international students spent significantly fewer hours participating in physical activity than male students, and students from North America 
showed the most active participation in physical activity. College students from four different cultures also demonstrated that females were less likely to participate in regular physical activity

than males. ${ }^{17}$ The author's results reiterated that physical activity between genders and cultures is prevalent. An additional study involved investigating physical activity patterns by assessing energy expenditures with pedometers placed on 31 subjects; the results of their study indicated that male and female students did not differ in total physical activity, substantiating the inconsistencies with self reported physical activity patterns. ${ }^{23}$

This study examined the characteristics and relationships between physical activity and college students, and analyzed which personal and demographic characteristics suggested physical activity patterns. Also examined were different patterns of exercising per week, reasons to exercise, attitudes toward exercise and which variables would lead to the propensity to exercise vigorously. A sample of 553 undergraduates was surveyed at two separate university student centers located in the South Atlantic region of the United States. University A, a large Division I school and its student recreation center, and University B, a smaller university and its mixed use center consisting of recreation and student union facilities. Results were combined for evaluation in this study.

\section{Methods}

In October 2007, a pilot study was administered at University B's Student Activity Center. A total of 68 pilot surveys were returned and analyzed. The pilot study showed there were specific questions that included complex tables that were frequently left unanswered. For this reason the final survey instrument was simplified and edited for more thorough completion of tables and questions. The final survey was administered in October, 2008 and the study was expanded to include both University A and University B. At both centers, tables were located in 
a central location adjacent to the primary ingress and egress points. Respondents were notified that the results of the study would be part of a doctoral dissertation, on average each survey took approximately 10 minutes to complete. No personal information was collected that could link the student's identification to a completed survey. Participants were given a free non-alcoholic drink for completing the questionnaire to encourage participation. The questionnaire queried participants about their usage and physical activity patterns, purpose of visit and satisfaction associated with various facets of their recreation experience. Surveys were collected at both institutions on three different days and times to ensure the sample included as diverse group of respondents as possible. A total of 553 surveys were collected, with 285 collected from UA and 268 surveys from UB.

University A is an NCAA Division I, Land Grant University located in a small town of 28,600. The university's population of 29,000 students doubles the size of the community. The 177,000 square foot $\$ 34$ million dollar recreation center opened July, 2001 and is heavily used by many students. University B, an NCAA Division II university, is also located in a small town of 19,000 people. The university has a population of 7,450 students and the $\$ 24$ million dollar student activity center opened in January, 2005.

\section{Measures}

Various demographic data were compiled; gender, ethnicity, enrollment status (12+ credits, <12 credits), years at university (1 through 4 years), living arrangements (in dorms/on campus, at home, off campus) and employment status (full-time, part-time, does not work). A final question categorized why the facility was usually used for; socialization (meeting friends,

eating, attending events) or recreation (sport, physical activity). A similar project in $2005^{3(\mathrm{p} 216)}$ studied similar demographic statistics (age, sex, race, marital status, membership in a fraternity or sorority, living situation, class standing and GPA) and assessed the relationships between 
physical activity and personal characteristics, For the purpose of this research, several demographic variables were replicated.

Questions were also asked pertaining to physical activity patterns, including how often one participated in exercise in a typical week for at least 30 minutes and enough to work up a sweat. A further distinction was made by asking how many times per week the participants partake in strenuous exercise (heart beats rapidly) and moderate activity (not exhausting).

Additionally, a question was asked indicating possible reasons for using the facility with the following choices: 1) for physical exercise, 2) to lose weight, 3) to reduce stress, 4) for relaxation, 5) to be with friends in my group, 6) to get away from other people, 7) to get away from the usual demands of life, 8) to reflect on my spiritual value. The participants were asked to circle the appropriate number on a scale of 1 to 5 (low to high) reasons for visiting the center. A final question asking respondents to select one of the above choices as the primary reason to use the facility was also included.

Lastly, questions were asked regarding opinions toward exercise, a likert scale indicating level of agreement or disagreement was included ( $1=$ strongly disagree to $5=$ strongly agree) These questions comprised of: 1) exercising is a good way to ensure I have good health, 2) exercising is a good time for me to catch up with my friends/family, 3) people who are important to me encourage me to exercise regularly, 4) exercising is a good way to spend time with people who are important to me, 5) it is important to me that my family and friends know I exercise, 6) in order to get the benefits of exercising, it has to be hard work, 7) exercise makes me feel good about my appearance.

Based on these questions, the following hypotheses were developed:

1. Determine overall similarities and differences in demographics. 
2. Summarize physical activity patterns of the college student population.

3. Assess queried statements indicating reasons to use the facility in a cohort of college students.

4. Evaluate opinions toward exercise and ascertain which variables influenced physical activity.

\section{Results}

Demographic results illustrated that male students (56.6\%) made up a majority of the respondents, while females comprised of $43.4 \%$ of the sample. The vast majority of respondents (90.3\%) were White, full-time students $(97.8 \%)$ with 12 or more credit hours. Just over half of the respondents $(52.7 \%)$ did not work and almost half $(47.3 \%)$ lived in off campus housing.

Overall, one third of the respondents $(33.1 \%)$ were first year students, $21.6 \%$ second year students, $18.5 \%$ third year students and $26.8 \%$ were in their fourth or higher year. Utilizing the facility for socialization (51\%) versus recreation/physical activity (49\%) was nearly evenly distributed.

Pertaining to research question two, and answering how often in a typical week a participant engages in physical activity for at least 30 minutes and enough to work up a sweat, the overall mean score was 3.47 times per week. Exercising strenuously with rapid heartbeats achieved a mean of 3.01 and moderate physical exercise noted a mean score of 2.51.

Results for research question three indicated an overwhelming primary reason to use the facility was for physical exercise $(63.7 \%)$ followed by, to be with friends in my group (16.9\%), to lose weight $(9.7 \%)$, to reduce stress $(2.5 \%)$, and for relaxation $(1.5 \%)$. The remaining items, to get away from the usual demands of life and to reflect on my spiritual value had less than a $1 \%$ response. Mean scores on the scale of 1 to 5 (low to high) for possible reasons to utilize the facility are listed in priority: for physical exercise (4.33), to reduce stress (3.85), to lose weight (3.78), for relaxation (3.56), to be with friends in my group (3.48), to get away from the usual 
demands of life (3.48), to get away from other people (2.95), and to reflect on my spiritual value (2.30).

When asking students why exercise was important to them on a level of agreement scale ( $1=$ strongly disagree to $5=$ strongly agree) and to answer research question number four regarding reasons to exercise, "exercising is a good way to ensure I have good health" had the highest mean score at 4.59. Following closely were the statements, "people who are important to me encourage me to exercise regularly" (4.40), and "exercise makes me feel good about my appearance" (4.36). "Exercise gives me more energy" and "exercise helps me deal with stress" both had a mean score of 4.32. Lastly the following statements rated lower, "in order to get the benefits of exercising, it has to be hard work" (3.89), "exercise is a good time for me to catch up with my friends/family" (3.33) and "it is important to me that my family and friends know I exercise" (3.37).

Additionally, when analyzing research question four, a comparison of means utilizing ttest and ANOVA statistics explained the significance of demographic variables (gender, ethnicity, enrollment status, years at university, living arrangements, employment status, social/recreation use) and how these variables influenced particular activity patterns and opinions of exercise. The following charts depict the two variables showing significance; living arrangements (in dorms/on campus, at home, off campus) and why the facility was usually used, for socialization (meeting friends, eating, attending events) or recreation (sport, physical activity). 
Table 1. Living Arrangements (in dorms/on campus, at home, off campus) -ANOVA statistic

\begin{tabular}{|l|l|l|l|l|}
\hline Reasons-Statements to exercise & $\begin{array}{l}\text { On } \\
\text { Campus }\end{array}$ & $\begin{array}{l}\text { At } \\
\text { Home }\end{array}$ & $\begin{array}{l}\text { Off } \\
\text { Campus }\end{array}$ & F-Value \\
\hline For physical exercise & Mean & \multicolumn{2}{|l|}{} & \\
\hline Be with friends in group & 4.27 & 4.12 & 4.45 & $4.259^{*}$ \\
\hline To get away from other people & 3.75 & 3.87 & 3.15 & $15.979^{* * *}$ \\
\hline Good way to spend time with people important to me & 3.17 & 2.64 & 2.92 & $5.126^{* *}$ \\
\hline
\end{tabular}

$* \mathrm{p}<.05, * * \mathrm{p}<.01, * * * \mathrm{p}<.001$

In order to better understand the influence of the socio-demographic variables on reasons for exercising, mean scores were examined across the three categories (on campus, at home, and off campus). Four reasons showed significantly different mean scores across the three categories. Respondents living at home reported the highest means scores for being with friends in a group (mean=3.87), and for good way to spend time with people important to me (mean=3.60). Students living at home also reported the lowest score for the item for physical exercise (mean=4.12), while students living off campus reported the highest mean score for this item (4.45). Respondents living on-campus reported the highest means score for the item to get away from other people (mean=3.17).

Table 2. Social or Physical (why the facility was used) - T-test statistic

\begin{tabular}{|l|l|l|l|}
\hline Exercise Patterns/Reasons-Statements to exercise & $\begin{array}{l}\text { Physical } \\
\text { Reasons }\end{array}$ & $\begin{array}{l}\text { Social } \\
\text { Reasons }\end{array}$ & T-test \\
\hline & Mean & \\
\hline \# per week physical exercise at least 30 minutes & 4.19 & 3.37 & $5.911^{* * *}$ \\
\hline For physical exercise & 4.66 & 4.05 & $87.751^{* * *}$ \\
\hline To lose weight & 3.98 & 3.59 & $4.012^{* * *}$ \\
\hline To reduce stress & 4.06 & 3.67 & $10.743^{* * *}$ \\
\hline Be with friends in group & 2.92 & 4.04 & $14.817^{* * *}$ \\
\hline To get benefits, exercise has to be hard work & 4.02 & 3.74 & $8.664^{* *}$ \\
\hline
\end{tabular}

$* * \mathrm{p}<.01, * * * \mathrm{p}<.001$

A second analysis was completed to ascertain the differences in respondents' responses concerning their primary reason for visiting the center. Students visiting the center to participate 
in physical activity were more likely to exercise for at least 30 minutes per week (mean=4.19) than those visiting for social reasons (3.37). Physically oriented students also reported higher means agreement scores for the items to lose weight, to reduce stress, and to get the benefits of exercising. Those students who visited the center primarily for social reasons were, obviously, more likely to visit to be with friends in groups (4.04) than students visiting primarily for physical activity (mean=2.92).

\section{Comment}

\section{Conclusions}

The purpose of this study was to examine the demographics of the combined student populations of two universities. In addition, this study explored the characteristics of physical activity patterns, reasons why participants utilize the recreation center, evaluated attitudes toward exercise, and assessed characteristics that influence physical activity.

The typical participant of this study was a White, full- time student with 12 or more credit hours, and was either a first or second year student who lived in off campus housing. In general, the student population engaged in at least 30 minutes of exercise 3.5 times per week. Strenuous exercise occurred 3 times per week and moderate exercise happened 2.5 times per week. These results are similar to the ACHA-NCHA, 2011study of 105,781 students that indicated $71 \%$ of participants exercised 0-3 days at moderate intensity for 30 minutes and $81 \%$ exercised vigorously $0-3$ days per week. ${ }^{13}$

The overwhelming response when asked to select one reason to visit the recreation center on campus was for physical exercise (67\%) and secondly to be with friends socially (17\%). When asked to rate a list of possible reasons why to visit the facility, to engage in physical exercise, to reduce stress, to lose weight, for relaxation and to be with friends were rated the 
highest for primary reasons to utilize the recreation facility. Recreation centers are built on college campuses to encourage physical activity, wellness and socialization among students outside of the classroom. These results indicate that students at both campuses are utilizing the recreation amenities for physical and social benefits.

Understanding why college students feel exercise is important and the need to establish regular physical activity patterns can have long-term effects on adult habits, prevent disease, and improve life-long health. ${ }^{3(\mathrm{p} 215)}$ The overall opinion was that "exercise is a good way to ensure I have good health," and secondly that "people who are important to me encourage me to exercise regularly." Other important highly rated reasons included "exercise makes me feel good about my appearance," "gives me more energy," and "helps me deal with stress." All statements indicate that this cohort of students chose reasons important to developing long-term patterns of physical activity.

Lastly, we examined variables that influenced physical activity patterns and opinions about exercise included living arrangements and rationale for using the facility for social or physical engagement. Previous research found predictors of physical activity and found that gender, race, being an athlete and being in a social fraternity or sorority were significant predictors of vigorous exercise in college student. ${ }^{3(\mathrm{p} 218)}$ This research study indicated that living arrangements (in dorms/on campus, at home, off campus) and why the facility was used for (socialization or physical activity) were significant variables influencing activity patterns and opinions of exercise.

This self-reported study showed similar results regarding patterns of physical activity and reasons to exercise as historical research studies of college students. Management at the two recreation facilities examined in this study should continue to assess and query interests of their 
students for future programming. The growth and continuation of wellness, physical activity and socialization activities for their students will offer opportunities for establishing long-term patterns of health and well-being for the student population.

\section{Limitations}

Limitations in the current study should be addressed for future research. Collecting data at two universities in close physical proximity with similar cultures can lead to generalization. The present findings may be limited; a comparison to a broader population of college students may possibly show differing results as participants were typically White, full- time student with 12 or more credit hours, and were either a first or second year student who lived in off campus housing. The questionnaire was distributed at the student recreation facilities, a building that attracts students interested in their well-being, it is plausible that those students who self-selected to participate in the study were more interested in health and wellness than those who chose not to participate.

Furthermore, it is uncertain if the issuing of a free non-alcoholic drink was a motivator to participate in the study. Research has indicated that there is a lack of multiple-level approaches and standard measurements of physical activity, there is not a uniformly accepted method, also a limiting factor when making a comparison among different samples. 


\section{References}

1. Body, D. The explosion of student recreation centers. Planning for Higher Education.1996; 25:7-13.

2. American College Health Association. Healthy Campus 2010: Making It Happen. Baltimore, MD; American College Health Association; 2002.

3. Miller K, Stated R.R, Rayens MK, Noland M. Levels and characteristics of physical activity among a college student cohort. Am J of Health Ed.,2005; 36(4);215-220.

4. Bray SR, Born HA. Transition to university and vigorous physical activity: Implications for health and psychological well being. J Am Coll Health. 2004;52(4):181-188.

5. Pate R, Pratt M, Blair N, et al. Physical activity and public health: a receommendation from the Centers for Disease Control and Prevention and the American College of Sports Medice. J Am Med Assoc. 1995;273:402-407.

6. Haskell WL., I-Min L, Pate RR., et al. Physical activity and public health: Updated recommendation for adults form the American College of Sports Medicine and the American Heart Association. Med Sci Sports and Exerc. 2007;1423-1434.

7. Healthy People Web site. http://www.healthypeople.gov/2020/default.aspx. Updated January 10, 2012. Accessed January 30, 2012.

8. U.S. Department of Health and Human Services. The Surgeon General's Vision for a Healthy and Fit Nation. Rockville, MD: U.S. Department of Health and Human Services, Office of the Surgeon General; 2010:1-17.

9. Wright RC, Pepe JA, Seidel KD, Dietz WH. Predicting obesity in young adulthood from childhood and parental obesity. New England J Med.1997; 37(13): 869-873.

10. Monteiro AC, Jeremic M, Budden MC. Can we have fries with that, please? Nutrition and physical activities among college students. Contemporary Issues in Education Research. 2010; 3(11):1-10.

11. American College Health Association. The American College Health AssociationNational College Health Assessment spring 2008 reference group data report (abridged). J Am Coll Health. 2009;57:477-488.

12. American College Health Assocaiton. The American College Health AssociationNational College Health Assessment spring 2003 reference group data report. J Am Coll Health. 2005;53:199-210. 
13. American College Health Association. American College Health Association-National College Health Assessment II reference group data report spring 2011. Hanover, MD: American College Health Association; 2011.

14. Keating X, Guan J, Castro J, Bridges DM. A Meta-analysis of college students' physical activity behaviors. J Am Coll Health. 2005; 54(2):116-125.

15. Bray SR., Kwan MYW. (2006). Physical activity is associated with better health and psychological well-being during transition to university life. J Am Coll Health. 2006;55(2):7782.

16. Hutchins M, Drolet JC,Ogletree R. Physical activity patterns and self-efficacy of selected college students. Health Educ. 2010;42(2):84-88.

17. Seo D-C, Torabi MR, Jiang N, Fernandez-Rojas X, Park B-H. Cross-cultural comparison of lack of regular physical activity among college students: Universal versus transversal. Int J Beh Med. 2009;16: 355-359.

18. Yoh T, Yang H, Gordon B. (2008). Status of participation in physical activity among international students attending colleges and universities in the United States. Coll Student J. 2008;42(4):1110-1117.

19. Sullum J, Clark M, King TK. Predictors of exercise relapse in a college population. J Am Health. 2000;48(4):175-181.

20. Kwan MYW, Bray SR, Ginis K. Predicting physical activity of first-year university students: An applicatin of the theory of planned behavior. J Am Coll Health. 2009;58(1):45-52.

21. Buckworth J, Nigg C. Physical activity, exercise, and sedentary behavior in college students. J Am Coll Health, 2004;55(1):28-34.

22. Mack MG, Shaddox LA. Changes in short-term attitudes toward physical activity and exercise of university personal wellness students. Coll Student J. 2004;38(4):587-594.

23. Behrens T, Dinger M. A preliminary investigation of college students' physical activity patterns. Am J Health Studies. 2003;18(2):169-172. 


\section{CONCLUSION}

Although located less than 30 miles from one another, West Virginia University (WVU) and Fairmont State University (FSU) are vastly different universities in size and character. WVU has separate buildings for a student recreation center and student union, whereas FSU has a combined facility which includes both a student union and recreation center. Significant differences were noted for nearly all of the social demographics at the two universities. WVU respondents were predominately White, and were much more likely to be male, FSU students were more likely to be part time students, more likely to be employed, and more likely to be first or second year students. FSU students were also much more likely to live in a dormitory or at home, while WVU students were much more likely to live in off-campus housing. Usage patterns as well showed distinct differences between these two student groups. WVU students were much more likely to report they used the facility for recreation only, while FSU students were more likely to use the facility for both recreation and socialization. WVU students were much more likely to report they used the facility for physical exercise than FSU students, and FSU students participated at the facility for socialization reasons about six times as much as WVU students. Similar to what is found in the literature, the most constraining item was a lack of time to exercise. This would lead to the conclusion that regardless of the type of facility, similar types of students recreate and socialize on college campuses at their perspective student recreation/activity centers.

Also examined was customer satisfaction at both university centers to explore service quality indicators as predictors of customer satisfaction utilizing a model to examine relationships. Participants at both universities were queried about their perceptions of the facility, information and service indicators and their overall satisfaction from utilizing their 
college recreation center. A comparison of the three domains (facilities, information and services) showed that each was significantly different between the two university facilities. Both student populations appreciate their facility, the services offered, and the accurate information provided. A question measuring the overall quality of experience of the recreation center on a typical visit (scale of 1-10), showed high mean values for both universities. WVU was rated slightly higher (mean $=8.56)$ when compared to FSU (mean=8.22). This single item indicator illustrates a high level of student customer satisfaction at both campus facilities. To determine how the items and domains predicted overall satisfaction within the two universities, multiple regression tests examined satisfaction within the two separate universities. Individual items within the three domains were regressed against the domains and then the domains were regressed against overall satisfaction. The regression model at FSU accounted for about 57\% of the variance associated with overall satisfaction, while WVU's regression model explained about $34 \%$ of variance. The differences in the results of the regression models between the two universities may be a function of the distinct differences in the structure of their recreation centers.

Lastly, when analyzing both college populations overall, characteristics of physical activity patterns, opinions and attitudes toward exercise, and which characteristics influence physical activity were evaluated. In general, the student population engaged in at least 30 minutes of exercise 3.5 times per week. Strenuous exercise occurred 3 times per week and moderate exercise happened 2.5 times per week. The overwhelming response when asked to select one reason to visit the recreation center on campus was for physical exercise (67\%) and secondly to be with friends socially (16.9\%). When asked to rate a list of possible reasons why to visit the facility, to engage in physical exercise, to reduce stress, to lose weight, for relaxation 
and to be with friends were rated the highest for primary reasons to utilize the recreation facility. Recreation centers are built on college campuses to encourage physical activity, wellness and socialization among students outside of the classroom. These results indicate that students at both campuses are utilizing the recreation amenities for physical and social benefits. The overall opinion was that "exercise is a good way to ensure I have good health," and secondly that "people who are important to me encourage me to exercise regularly." All statements indicate that this cohort of students chose reasons important to developing long-term patterns of physical activity. Lastly, we examined variables that influenced physical activity patterns and opinions about exercise included living arrangements and rationale for using the facility for social or physical engagement. This research study indicated that living arrangements (in dorms/on campus, at home, off campus) and why the facility was used for (socialization or physical activity) were significant variables influencing activity patterns and opinions of exercise. The growth and continuation of wellness, physical activity and socialization activities will offer opportunities for establishing long-term patterns of health and well-being for the student population.

University administrators have begun to recognize the significance of how students utilize their out-of-class time. It is important that students feel connected to their campus and social community, and student centers have proven to be beneficial to the overall college experience, be if for recreation only, socialization only, or both.

With the construction of the FSU student activity center, which includes both recreation and student union facilities for FSU, a social environment attracted students to the facility. Students could then observe friends exercising and recreating and consider joining them. This study established that students at WVU with two separate facilities (student union and student 
recreation center) that students visited the recreation center primarily for exercise.

Prior to construction, academic administration typically assess the requests of students and their physical and social needs. It is recommended that administrators conduct a follow-up study to understand why their students are or are not utilizing the facilities. In a broad sense, recreation and socialization are demonstrated to be reasons to visit and participate. The most popular reasons why both facilities were visited were for physical exercise, to lose weight, to be with friends, to reduce stress and to get away from the usual demands of life. All of these categories can be attributed to physical, recreation and social needs. When asking why individuals may not utilize the facility, both WVU and FSU indicate that students do not have enough time or are too tired to exercise; they lack motivation to exercise, are busy with other activities or disdain a crowded facility. Modern facilities, innovative and varied programs, and friendly and creative staff are integral to the success of the recreation needs of the university student. For managerial purposes and implications, recreation administration should continually assess their students to determine if and how they are utilizing the facilities that have been specifically built for their needs. Further investigation, follow-up surveys and evaluations are integral in the field of recreation for both researchers and management to continually evaluate trends, needs and responses of student participants. 


\section{APPENDIX}

\section{Fairmont State University Questionnaire}

The results of this study will be tabulated and provided to West Virginia University as part of a $\mathrm{PhD}$ dissertation. Benefits from this study include helping to improve the recreation opportunities at Fairmont State University and Pierpont Community \& Technical College. There is no payment for completing this survey, but your input is important. The survey is confidential-your name will not be asked and you will not be identified. You may be assured that your answers will not be connected with you. Your participation in this study is voluntary and you have the right not to answer any questions. Student rank, class or grades are not affected by refusal to participate or withdrawal.

\section{WILL YOU PARTICIPATE IN THIS STUDY?}

If YES: Thank You! (Then continue with the survey)

If NO: Thank you for your time.

First, we would like to find out a little about your knowledge and use of the Falcon Center at Fairmont State University.

1. Were you aware that FSU has a Student Center (Falcon Center) which includes recreation and fitness areas? (please check one box)

$\square$ Yes $\square$ No $\rightarrow$ (skip to...\#9)

2. How did you first find out about the FSU Falcon Center?

(please check one)

$\begin{array}{ll}\square \text { Word of mouth } & \square \text { Newspaper article } \\ \square \text { Driving/Walking past } & \square \text { Brochure } \\ \square \text { Internet web site } & \square \text { Email } \\ \square \text { Orientation } & \square \text { Other (please specify) }\end{array}$

3. When you use the FSU Falcon Center, do you usually use it for: (please check one)

$\square$ Socialization (meeting friends, eating at dining areas, attending student events)

Q Recreation (sport, physical activity, leisure, or other types of relaxation)

$\square$ Both recreation and socialization

$\square$ Other (please specify)

4. When was the first time you used the FSU Falcon Center for recreation?

(please check one)

$\square$ Never, have not used the Falcon Center $\square$ Less than 1 month ago $\square$ 1-3 months ago

( 4-6 months ago $\square$ 7-11 months ago $\square$ 1-3 years ago $\square$ Greater than 3 years ago

5. In a typical week, how often do you visit the Falcon Center for socialization? per week

6. Considering a typical week, how often do you engage in physical activity at least 30 minutes and 
enough to work up a sweat $?$

Strenuous physical activity (heart beats rapidly) times per week

(i.e. running, jogging, soccer, basketball, vigorous swimming, intense biking, stair stepping)

Moderate physical activity (not exhausting) times per week

(i.e. fast walking, easy bicycling, volleyball, easy swimming, dancing)

Mild physical activity (Minimal effort) times per week (i.e. yoga, easy walking)

7a. Below is a list of possible reasons why people visit the Falcon Center. Please circle the appropriate number for each item explaining your reason for visiting the center.

\begin{tabular}{|c|c|c|c|c|c|}
\hline REASONS & & & & & Excellent \\
\hline For physical exercise & 1 & 2 & 3 & 4 & 5 \\
\hline To lose weight & 1 & 2 & 3 & 4 & 5 \\
\hline To reduce stress & 1 & 2 & 3 & 4 & 5 \\
\hline For relaxation & 1 & 2 & 3 & 4 & 5 \\
\hline To be with friends in my group & 1 & 2 & 3 & 4 & 5 \\
\hline To get away from other people & 1 & 2 & 3 & 4 & 5 \\
\hline $\begin{array}{l}\text { To get away from the usual demands } \\
\text { of life }\end{array}$ & 1 & 2 & 3 & 4 & 5 \\
\hline To reflect on my spiritual value & 1 & 2 & 3 & 4 & 5 \\
\hline Other please specify: & 1 & 2 & 3 & 4 & 5 \\
\hline
\end{tabular}


7b. Also, select $\underline{\mathbf{O N E}}$ item (with a check) that is your primary reason for using the FSU Falcon Center?

\begin{tabular}{|l|l|}
\hline REASONS & Primary Reason \\
\hline For physical exercise & \\
\hline To lose weight & \\
\hline To reduce stress & \\
\hline For relaxation & \\
\hline To be with friends in my group & \\
\hline To get away from other people & \\
\hline To get away from the usual demands of life & \\
\hline To reflect on my spiritual value & \\
\hline Other please specify: & \\
\hline
\end{tabular}

8. In a typical week, which of the following activities do you participate at the Falcon Center? Which is your primary choice? (please check activities and primary choice)

\begin{tabular}{|l|l|l|}
\hline Activity & $\begin{array}{l}\text { (Can check more } \\
\text { than one activity) }\end{array}$ & $\begin{array}{l}\text { Primary Choice } \\
\text { (check only one) }\end{array}$ \\
\hline Walk & & \\
\hline Jog or run & & \\
\hline Swim & & \\
\hline Use exercise machines & & \\
\hline Lift "free" weights & & \\
\hline $\begin{array}{l}\text { Play basketball, volleyball, } \\
\text { soccer, etc. }\end{array}$ & & \\
\hline Fitness Classes & & \\
\hline Participate in Intramurals & & \\
\hline Other, please specify & & \\
\hline
\end{tabular}

Please select your primary choice from the activities listed above. 
9. We are interested in knowing what facilities/services in the Falcon Center are most important to you. Please tell me your level of satisfaction for each of the below listed items (circle appropriate number)

\begin{tabular}{|l|l|l|l|l|l|l|}
\hline & \multicolumn{5}{|c|}{ SATISFACTION } \\
\hline FACILITIES/SERVICES & \multicolumn{2}{|c|}{$\begin{array}{c}\text { Very } \\
\text { Unsatisfied }\end{array}$} & $\begin{array}{l}\text { Not } \\
\text { Applicable }\end{array}$ \\
\hline Convenient location & 1 & 2 & 3 & 4 & 5 & NA \\
\hline Visibility of staff & 1 & 2 & 3 & 4 & 5 & NA \\
\hline Appearance and maintenance of the area & 1 & 2 & 3 & 4 & 5 & NA \\
\hline Safety and security of the area & 1 & 2 & 3 & 4 & 5 & NA \\
\hline Ease of obtaining information & 1 & 2 & 3 & 4 & 5 & NA \\
\hline Courteous and friendly staff & 1 & 2 & 3 & 4 & 5 & NA \\
\hline Current and accurate information about activities in the building & 1 & 2 & 3 & 4 & 5 & NA \\
\hline Opportunity to offer suggestions & 1 & 2 & 3 & 4 & 5 & NA \\
\hline Lighting & 1 & 2 & 3 & 4 & 5 & NA \\
\hline Bathrooms/locker rooms & 1 & 2 & 3 & 4 & 5 & NA \\
\hline Exercise equipment & 1 & 2 & 3 & 4 & 5 & NA \\
\hline Multi-purpose courts (basketball, volleyball, soccer) & 1 & 2 & 3 & 4 & 5 & NA \\
\hline Fitness rooms for exercise & 1 & 2 & 3 & 4 & 5 & NA \\
\hline Hours of facility & 1 & 2 & 3 & 4 & 5 & NA \\
\hline Available programs & 1 & 2 & 3 & 4 & 5 & NA \\
\hline Other (please specify) & 1 & 2 & 3 & 4 & 5 & NA \\
\hline
\end{tabular}

\section{Now, we'd like to know about your level of physical activity.}

10. At this time, would you say that your overall health is: (check one)

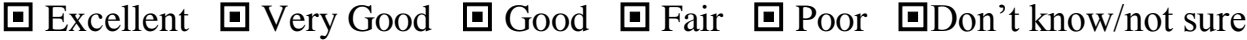

11. Experts say that getting regular physical activity means doing moderate activities, such as walking briskly, for at least $\mathbf{3 0}$ minutes on 5 or more days of the week. At this time, are you regularly physically active according to the definition above? (check one)

$\square$ no, and I do not intend to in the next 6 months

$\square$ no, but I intend to in the next 6 months

$\square$ yes, I have been for less than 6 months

$\square$ yes, I have been for more than 6 months 


\section{We would now like to ask you a few questions about your opinions regarding exercise.}

12. Pease indicate your level of agreement or disagreement in regards to the following statements (please circle the appropriate number)

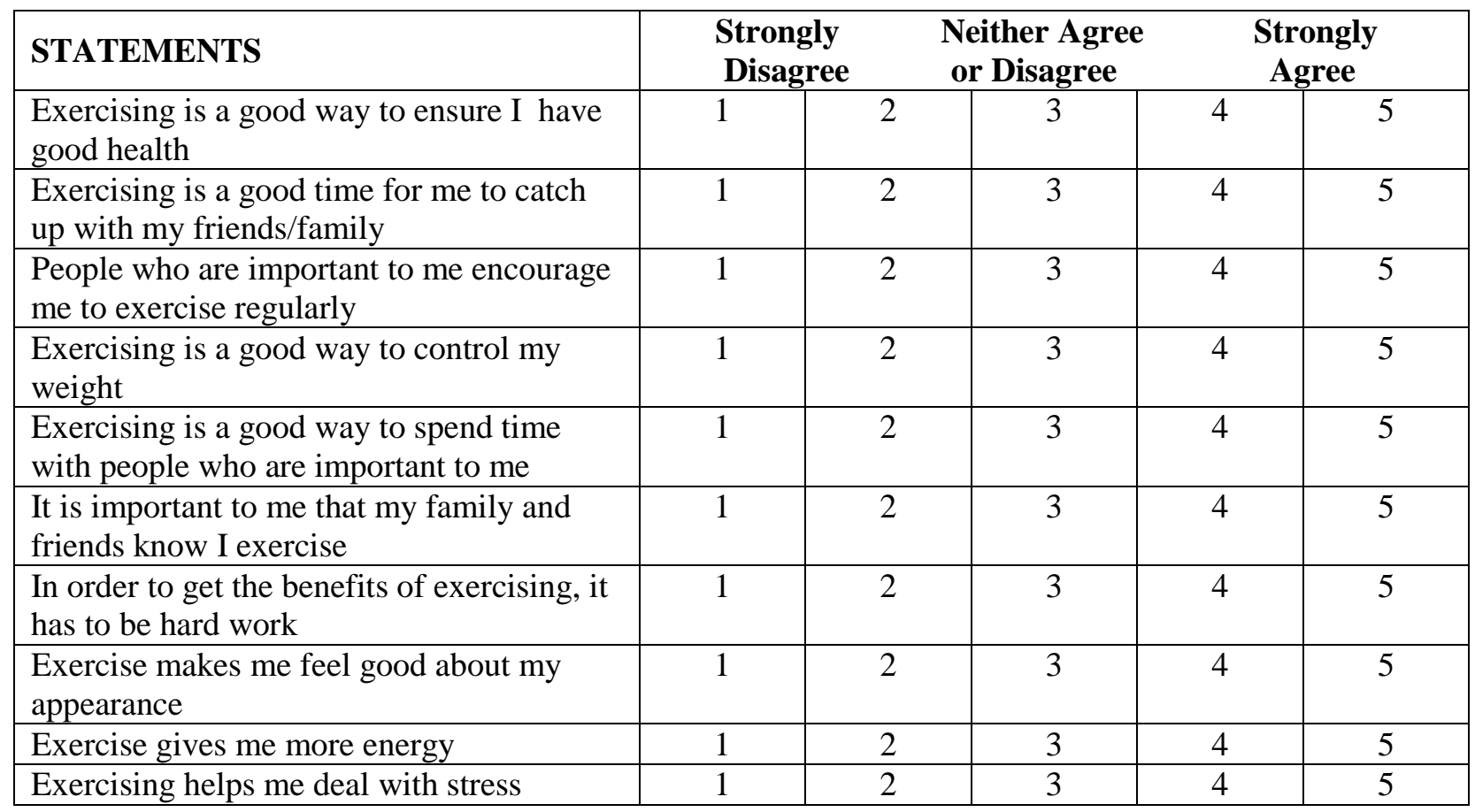


13. Listed below are some reasons why people may not utilize the Falcon Center as often as they would like. In a typical week, please tell us if each item is a major reason, a minor reason, or not a reason why you participate as often as you would like to? (Please respond to each of these items)

\begin{tabular}{|l|c|c|c|c|}
\hline Reason & $\begin{array}{c}\text { Major } \\
\text { Reason }\end{array}$ & $\begin{array}{c}\text { Minor } \\
\text { Reason }\end{array}$ & $\begin{array}{c}\text { Not a } \\
\text { Reason }\end{array}$ & $\begin{array}{c}\text { Not Sure/ } \\
\text { Don't Know }\end{array}$ \\
\hline Don't have enough time to exercise & 1 & 2 & 3 & N/S \\
\hline Have no way to get to there & 1 & 2 & 3 & N/S \\
\hline $\begin{array}{l}\text { Lack of information about recreation } \\
\text { opportunities }\end{array}$ & 1 & 2 & 3 & N/S \\
\hline Fear of injury & 1 & 2 & 3 & N/S \\
\hline Too busy with other recreation activities & 1 & 2 & 3 & N/S \\
\hline I feel intimidated due to body image & 1 & 2 & 3 & N/S \\
\hline $\begin{array}{l}\text { I am unknowledgeable about how to use } \\
\text { equipment }\end{array}$ & 1 & 2 & 3 & N/S \\
\hline Poor health & 1 & 2 & 3 & N/S \\
\hline Don't have anyone to go with & 1 & 2 & 3 & N/S \\
\hline Falcon Center is too far away & 1 & 2 & 3 & N/S \\
\hline Falcon Center is too crowded & 1 & 2 & 3 & N/S \\
\hline The hours of the facility are not convenient & 1 & 2 & 3 & N/S \\
\hline Like to do other things for recreation more & 1 & 2 & 3 & N/S \\
\hline $\begin{array}{l}\text { Fear of prejudice from others based on my } \\
\text { racial/ethnic identity }\end{array}$ & 1 & 2 & 3 & N/S \\
\hline I am too tired to exercise & 1 & 2 & 3 & N/S \\
\hline I get plenty of exercise at my job & 1 & 2 & 3 & N/S \\
\hline I don't have the motivation to exercise & 1 & 2 & 3 & N/S \\
\hline $\begin{array}{l}\text { Not aware of recreation opportunities at the } \\
\text { Falcon Center }\end{array}$ & & 2 & 3 & N/S \\
\hline $\begin{array}{l}\text { Recreation opportunities that I like to participate } \\
\text { in are not available at the Falcon Center }\end{array}$ & & & & \\
\hline Negative attitudes from employees & & & & \\
\hline $\begin{array}{l}\text { Are there any other reasons you haven't recreated } \\
\text { at the Falcon Center as often as desired over the past year? } \\
\text { Please explain }\end{array}$ & & & & \\
\hline
\end{tabular}

14. Do you participate in Intramural programs?
$\square$ Yes
口 No

15. Do you participate in student events (i.e. concerts, carnivals) at the Falcon Center?

田es

口 No 


\section{Next, we would like to hear about your overall experiences at the FSU Falcon Center.}

16. How would you rate the overall quality of the Facilities at Falcon Center?

\begin{tabular}{|c|c|c|c|c|c|c|}
\hline & $\begin{array}{l}\text { Not at all } \\
\text { Satisfied }\end{array}$ & $\begin{array}{c}\text { Somewhat } \\
\text { Satisfied }\end{array}$ & $\begin{array}{c}\text { Moderately } \\
\text { Satisfied }\end{array}$ & $\begin{array}{c}\text { Very } \\
\text { Satisfied }\end{array}$ & $\begin{array}{l}\text { Extremely } \\
\text { Satisfied }\end{array}$ & $\begin{array}{c}\text { Not } \\
\text { Applicable }\end{array}$ \\
\hline Facilities & 1 & 2 & 3 & 4 & 5 & \\
\hline
\end{tabular}

17. How would you rate the overall quality of Services at the Falcon Center?

\begin{tabular}{|l|c|c|c|c|c|c|}
\multicolumn{1}{c}{} & $\begin{array}{c}\text { Not at all } \\
\text { Satisfied }\end{array}$ & $\begin{array}{c}\text { Somewhat } \\
\text { Satisfied }\end{array}$ & $\begin{array}{c}\text { Moderately } \\
\text { Satisfied }\end{array}$ & $\begin{array}{c}\text { Very } \\
\text { Satisfied }\end{array}$ & $\begin{array}{c}\text { Extremely } \\
\text { Satisfied }\end{array}$ & $\begin{array}{c}\text { Not } \\
\text { Applicable }\end{array}$ \\
\hline Services & 1 & 2 & 3 & 4 & 5 & \\
\hline
\end{tabular}

18. How would you rate the overall quality of Information at the Falcon Center?

\begin{tabular}{|l|c|c|c|c|c|c|}
\multicolumn{1}{c|}{} & $\begin{array}{c}\text { Not at all } \\
\text { Satisfied }\end{array}$ & $\begin{array}{c}\text { Somewhat } \\
\text { Satisfied }\end{array}$ & $\begin{array}{c}\text { Moderately } \\
\text { Satisfied }\end{array}$ & $\begin{array}{c}\text { Very } \\
\text { Satisfied }\end{array}$ & $\begin{array}{c}\text { Extremely } \\
\text { Satisfied }\end{array}$ & $\begin{array}{c}\text { Not } \\
\text { Applicable }\end{array}$ \\
\hline Information & 1 & 2 & 3 & 4 & 5 & \\
\hline
\end{tabular}

19. On a scale of $\mathbf{1} \mathbf{- 1 0}$, how would you rate your overall quality of experience of the Falcon Center for a typical visit?

\section{Finally, we'd like to know a little about you.}

20. Are you Hispanic or Latino $\square$ No $\square$ Yes

21. Which racial group(s) do you identify with? Check all that apply.
品hite
口 Black/African American
口Asian
口American Indian/ Alaska Native GNative Hawaiian or other Pacific Islander

22. Gender: $\square$ Female $\square$ Male

23. What is your current enrollment status here at FSU?

口 I am enrolled full time (12+ credits)

$\square$ I am enrolled part time ( $<12$ credits)

24. How many semesters including the current semester have you attended at Fairmont State University?

25. Where do you live while attending school at FSU?

In the dorms/campus apartments

At home

口 Off campus housing

26. Are you currently employed (pick one)?

$\square$ Yes, I work full time

$\square$ Yes, I work part time

$\square$ No, I don’t currently work 
27. What positive comments do you have about the Falcon Center?

28. What improvements would you suggest for the Falcon Center? 


\section{Fairmont State University - Summary of Positive Comments}

What positive comments do you have about the Falcon Center?

A good variety of things to do

At least there is a pool

Clean and ease of access, large food selection

Convenient, clean, never too crowded - everything I need is there.

Everyone is friendly

Friendly staff, especially the lifeguards

Good for recreational activities

Good location to hang out

Good place to meet friends

Good place to socialize

Good way to catch up with friends

Great equipment and nicely maintained

Great fitness center

Great place for many reasons, socializing, physical activity, well kept.

Great place to chill and do whatever

Great weight room and track

I am satisfied with all the facilities, equipment, intramurals and different recreation provided.

Staff is very helpful

I feel the falcon center is very well run and has a lot of good information.

I like the overall atmosphere, everyone seems to be happy and it's always kept clean.

I live at the Falcon Center.

I love all the amenities provided for students. Falcon center is central to campus and a natural gathering place.

I love it and nice facility, best I have seen at a college.

I love it, it's a great thing to have for the campus.

I love the Falcon Center. Out of all the colleges I've seen, even WVU, our center is the best rec center.

I love the music and atmosphere

I love working out, I've made a lot of new friends by going to the gym and hanging near the Nickel and food court.

I really like how we can work out and swim, shoot basketball -- basically how we get to exercise.

I really like the Falcon Center, it is a nice place to go hang out and there is a lot of stuff to do here when you're bored.

I think it is a nice atmosphere for meeting friends, catching up on homework and sheer relaxation, plus the food is good.

I think that they offer a lot of fitness classes, also they try to fit everyone's likes and that is a good thing.

I think the equipment we have is very good, a lot better than when it was in the Feaster Center my freshman year.

If there are problems and flaws, then I don't notice them. 
It is always very clean and everyone is very friendly. The temperature is always just right.

It is good for us to be away from tension.

It is located in a good location. A very ideal place to relax, eat, and socializes.

It is a good place to go, I come here 5 days a week to meet friends, workout and eat, and relax between classes.

It's always a good place to catch up with old friends and meet new people.

It's an all around good place, it's everything in one building.

It's very clean and good hours

Looks good for school image

Looks impressive from the outside

Nice quiet place to hang out and use the wireless to study.

Seems great for local/on campus students

The staff is extremely friendly and helpful

The weight room staff is very helpful

The workout facilities are nice, it's a good place to just hang out and relax.

There are a lot of different things to do. Falcon Center seems to try to get what students want and voice their opinions about.

There are a variety of things to do in the Falcon Center and employees are helpful and courteous.

There is always a chance to get involved with things, hours of operation are great.

Very friendly director and good hours

\section{Fairmont State University - Summary of Improvements}

\section{What improvements would you suggest for the Falcon Center?}

A larger pool and steam room

A lot of people don't like the cafe being on top

A way to get information out better

Better food in Nickel, more times for fitness classes

Big TV's for sports

Climbing wall

Different times for fitness classes

Everyone in the Falcon center can watch you exercise. In some ways this can be encouraging but for me, the open feeling of the workout room is uncomfortable.

Group runs/walks. Increase sofa and couches

Guests shouldn't have to pay $\$ 5$ to enter

Hours need to be longer, more variation with food

Improve the building foundation, it rattles. The toilets are too close to the toilet paper dispensers.

Install something like a rock climbing wall or offer martial arts classes.

Lighting in fitness area brighter

Locks for locker rooms

Longer hours in the cafeteria

Longer hours on weekends 
Lower prices on food and items in bookstore

Make the pool open at more convenient times

More available staff

More classes offered early in morning

More room for socializing, Nickel area gets very crowded at times

Need pool tables and ping pong

Open 24 hours 


\section{West Virginia University Questionnaire}

The results of this study will be tabulated and provided to West Virginia University as part of a PhD dissertation. Benefits from this study include helping to improve the recreation opportunities at West Virginia University. There is no payment for completing this survey, but your input is important. The survey is confidential-your name will not be asked and you will not be identified. You may be assured that your answers will not be connected with you. Your participation in this study is voluntary and you have the right not to answer any questions. Student rank, class or grades are not affected by refusal to participate or withdrawal.

WILL YOU PARTICIPATE IN THIS STUDY?

If YES: Thank You! (Then continue with the survey)

If NO: Thank you for your time.

\section{First, we would like to find out a little about your knowledge and use of the WVU}

Recreation Center at West Virginia University.

1. How did you first find out about the WVU Rec Center?

(please check one)
Word of mouth
( Newspaper article
Driving/Walking past
Brochure
Internet web site
Email
回 Orientation
O Other (please specify)

2. When you use the WVU Rec Center, do you usually use it for: (please check one)

$\square$ Socialization (meeting friends, eating at dining area, attending student events)

Recreation (sport, physical activity, leisure, or other types of relaxation)

Both recreation and socialization

$\square$ Other (please specify)

3. When was the first time you used the WVU Rec Center for recreation?

(please check one)

$\square$ Never, have not used the WVU Rec Center $\square$ Less than 1 month ago $\square$ 1-3 months ago

( 4-6 months ago $\square$ 7-11 months ago $\square$ 1-3 years ago $\square$ Greater than 3 years ago

4. In a typical week, how often do you visit the WVU Rec Center for socialization? per week

5. Considering a typical week, how often do you engage in physical activity at least 30 minutes and enough to work up a sweat ?

Strenuous physical activity (heart beats rapidly) times per week

(i.e. running, jogging, basketball, vigorous swimming, intense biking, stair stepping)

Moderate physical activity (not exhausting)

(i.e. fast walking, easy bicycling, volleyball, easy swimming, times per week dancing) 
(i.e. yoga, easy walking)

6a. Below is a list of possible reasons why people visit the WVU Rec Center. Please circle the appropriate number for each item explaining your reason for visiting the center.

\begin{tabular}{|c|c|c|c|c|c|}
\hline REASONS & \multicolumn{4}{|c|}{ Awful } & Excellent \\
\hline For physical exercise & 1 & 2 & 3 & 4 & 5 \\
\hline To lose weight & 1 & 2 & 3 & 4 & 5 \\
\hline To reduce stress & 1 & 2 & 3 & 4 & 5 \\
\hline For relaxation & 1 & 2 & 3 & 4 & 5 \\
\hline To be with friends in my group & 1 & 2 & 3 & 4 & 5 \\
\hline To get away from other people & 1 & 2 & 3 & 4 & 5 \\
\hline $\begin{array}{l}\text { To get away from the usual demands } \\
\text { of life }\end{array}$ & 1 & 2 & 3 & 4 & 5 \\
\hline To reflect on my spiritual value & 1 & 2 & 3 & 4 & 5 \\
\hline Other please specify: & 1 & 2 & 3 & 4 & 5 \\
\hline
\end{tabular}

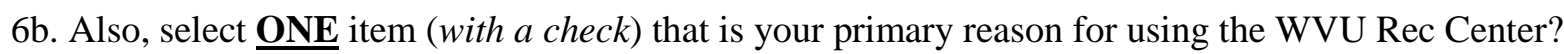

\begin{tabular}{|l|l|}
\hline \multicolumn{1}{|c|}{ REASONS } & Primary Reason \\
\hline For physical exercise & \\
\hline To lose weight & \\
\hline To reduce stress & \\
\hline For relaxation & \\
\hline To be with friends in my group & \\
\hline To get away from other people & \\
\hline To get away from the usual demands of life & \\
\hline To reflect on my spiritual value & \\
\hline Other please specify: & \\
\hline
\end{tabular}


7. In a typical week, which of the following activities do you participate at the WVU Rec Center? Which is your primary choice? (please check activities and primary choice)

\begin{tabular}{|l|l|l|}
\hline \multicolumn{1}{|c|}{ Activity } & $\begin{array}{c}\text { (Can check more } \\
\text { than one activity) }\end{array}$ & $\begin{array}{c}\text { Primary Choice } \\
\text { (check only one) }\end{array}$ \\
\hline Walk & & \\
\hline Jog or run & & \\
\hline Swim & & \\
\hline Use exercise machines & & \\
\hline Lift "free" weights & & \\
\hline Play basketball, volleyball & & \\
\hline $\begin{array}{l}\text { Play racquetball, squash, } \\
\text { badminton }\end{array}$ & & \\
\hline Fitness Classes & & \\
\hline Use the climbing wall & & \\
\hline $\begin{array}{l}\text { Other, please specify } \\
\text { Plase }\end{array}$ & & \\
\hline
\end{tabular}

Please select your primary choice from the activities listed above.

8. We are interested in knowing what facilities/services in the WVU Rec Center are most important to you. Please tell me your level of satisfaction for each of the below listed items (circle appropriate number)

\begin{tabular}{|c|c|c|c|c|c|c|}
\hline \multirow{3}{*}{$\begin{array}{l}\text { FACILITIES/SERVICES } \\
\text { Convenient location }\end{array}$} & \multicolumn{6}{|c|}{$\begin{array}{l}\text { SATISFACTION } \\
\end{array}$} \\
\hline & \multicolumn{3}{|c|}{$\begin{array}{c}\text { Very } \\
\text { Unsatisfied }\end{array}$} & \multicolumn{2}{|c|}{$\begin{array}{c}\text { Very } \\
\text { Satisfied }\end{array}$} & \multirow{2}{*}{$\begin{array}{c}\text { Not } \\
\text { Applicable } \\
\text { NA }\end{array}$} \\
\hline & 1 & 2 & 3 & 4 & 5 & \\
\hline Visibility of staff & 1 & 2 & 3 & 4 & 5 & NA \\
\hline Appearance and maintenance of the area & 1 & 2 & 3 & 4 & 5 & NA \\
\hline Safety and security of the area & 1 & 2 & 3 & 4 & 5 & NA \\
\hline Ease of obtaining information & 1 & 2 & 3 & 4 & 5 & NA \\
\hline Courteous and friendly staff & 1 & 2 & 3 & 4 & 5 & NA \\
\hline Current and accurate information about activities in the building & 1 & 2 & 3 & 4 & 5 & NA \\
\hline Opportunity to offer suggestions_- & 1 & 2 & 3 & 4 & 5 & NA \\
\hline Lighting & 1 & 2 & 3 & 4 & 5 & NA \\
\hline Bathrooms/locker rooms & 1 & 2 & 3 & 4 & 5 & NA \\
\hline Exercise equipment & 1 & 2 & 3 & 4 & 5 & NA \\
\hline Multi-purpose courts (basketball, volleyball, badminton) & 1 & 2 & 3 & 4 & 5 & NA \\
\hline Fitness rooms for exercise & 1 & 2 & 3 & 4 & 5 & NA \\
\hline Hours of facility & 1 & 2 & 3 & 4 & 5 & NA \\
\hline Available programs & 1 & 2 & 3 & 4 & 5 & NA \\
\hline Other (please specify) & 1 & 2 & 3 & 4 & 5 & NA \\
\hline
\end{tabular}

Now, we'd like to know about your level of physical activity. 
9. At this time, would you say that your overall health is: (check one)

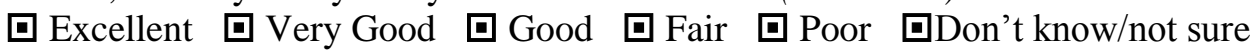

10. Experts say that getting regular physical activity means doing moderate activities, such as walking briskly, for at least $\mathbf{3 0}$ minutes on 5 or more days of the week. At this time, are you regularly physically active according to the definition above? (check one)

$\square$ no, and I do not intend to in the next 6 months

$\square$ no, but I intend to in the next 6 months

$\square$ yes, I have been for less than 6 months

$\square$ yes, I have been for more than 6 months

\section{We would now like to ask you a few questions about your opinions regarding exercise.}

11. Please indicate your level of agreement or disagreement in regards to the following statements (please circle the appropriate number)

\begin{tabular}{|l|c|c|c|c|c|}
\hline \multicolumn{1}{|c|}{ STATEMENTS } & \multicolumn{3}{c}{$\begin{array}{c}\text { Strongly } \\
\text { Disagree }\end{array}$} & \multicolumn{2}{c|}{$\begin{array}{c}\text { Neither Agree } \\
\text { or Disagree }\end{array}$} \\
\hline $\begin{array}{l}\text { Exercising is a good way to ensure I have } \\
\text { good health }\end{array}$ & 1 & 2 & 3 & 4 & 5 \\
\hline $\begin{array}{l}\text { Exercising is a good time for me to catch } \\
\text { up with my friends/family }\end{array}$ & 1 & 2 & 3 & 4 & 5 \\
\hline $\begin{array}{l}\text { People who are important to me encourage } \\
\text { me to exercise regularly }\end{array}$ & 1 & 2 & 3 & 4 & 5 \\
\hline $\begin{array}{l}\text { Exercising is a good way to control my } \\
\text { weight }\end{array}$ & 1 & 2 & 3 & 4 & 5 \\
\hline $\begin{array}{l}\text { Exercising is a good way to spend time } \\
\text { with people who are important to me }\end{array}$ & 1 & 2 & 3 & 4 & 5 \\
\hline $\begin{array}{l}\text { It is important to me that my family and } \\
\text { friends know I exercise }\end{array}$ & 1 & 2 & 3 & 4 & 5 \\
\hline $\begin{array}{l}\text { In order to get the benefits of exercising, it } \\
\text { has to be hard work }\end{array}$ & 1 & 2 & 3 & 4 & 5 \\
\hline $\begin{array}{l}\text { Exercise makes me feel good about my } \\
\text { appearance }\end{array}$ & 1 & 2 & 3 & 4 & 5 \\
\hline Exercise gives me more energy & 1 & 2 & 3 & 4 & 5 \\
\hline Exercising helps me deal with stress & 1 & 2 & 3 & 4 & 5 \\
\hline
\end{tabular}


12. Listed below are some reasons why people may not utilize the WVU Rec Center as often as they would like. In a typical week, please tell us if each item is a major reason, a minor reason, or not a reason why you participate as often as you would like to? (Please respond to each of these items)

\begin{tabular}{|c|c|c|c|c|}
\hline Reason & $\begin{array}{l}\text { Major } \\
\text { Reason }\end{array}$ & $\begin{array}{l}\text { Minor } \\
\text { Reason }\end{array}$ & $\begin{array}{c}\text { Not a } \\
\text { Reason }\end{array}$ & $\begin{array}{c}\text { Not Sure/ } \\
\text { Don't Know }\end{array}$ \\
\hline Don't have enough time to exercise & 1 & 2 & 3 & $\mathrm{~N} / \mathrm{S}$ \\
\hline Have no way to get to there & 1 & 2 & 3 & $\mathrm{~N} / \mathrm{S}$ \\
\hline $\begin{array}{l}\text { Lack of information about recreation } \\
\text { opportunities }\end{array}$ & 1 & 2 & 3 & $\mathrm{~N} / \mathrm{S}$ \\
\hline Fear of injury & 1 & 2 & 3 & $\mathrm{~N} / \mathrm{S}$ \\
\hline Too busy with other recreation activities & 1 & 2 & 3 & $\mathrm{~N} / \mathrm{S}$ \\
\hline I feel intimidated due to body image & 1 & 2 & 3 & $\mathrm{~N} / \mathrm{S}$ \\
\hline $\begin{array}{l}\text { I am unknowledgeable about how to use } \\
\text { equipment }\end{array}$ & 1 & 2 & 3 & $\mathrm{~N} / \mathrm{S}$ \\
\hline Poor health & 1 & 2 & 3 & $\mathrm{~N} / \mathrm{S}$ \\
\hline Don't have anyone to go with & 1 & 2 & 3 & $\mathrm{~N} / \mathrm{S}$ \\
\hline WVU Rec Center is too far away & 1 & 2 & 3 & $\mathrm{~N} / \mathrm{S}$ \\
\hline WVU Rec Center is too crowded & 1 & 2 & 3 & $\mathrm{~N} / \mathrm{S}$ \\
\hline The hours of the facility are not convenient & 1 & 2 & 3 & $\mathrm{~N} / \mathrm{S}$ \\
\hline Like to do other things for recreation more & 1 & 2 & 3 & $\mathrm{~N} / \mathrm{S}$ \\
\hline $\begin{array}{l}\text { Fear of prejudice from others based on my } \\
\text { racial/ethnic identity }\end{array}$ & 1 & 2 & 3 & $\mathrm{~N} / \mathrm{S}$ \\
\hline I am too tired to exercise & 1 & 2 & 3 & $\mathrm{~N} / \mathrm{S}$ \\
\hline I get plenty of exercise at my job & 1 & 2 & 3 & $\mathrm{~N} / \mathrm{S}$ \\
\hline I don't have the motivation to exercise & 1 & 2 & 3 & $\mathrm{~N} / \mathrm{S}$ \\
\hline $\begin{array}{l}\text { Not aware of recreation opportunities at the } \\
\text { WVU Rec Center }\end{array}$ & 1 & 2 & 3 & $\mathrm{~N} / \mathrm{S}$ \\
\hline $\begin{array}{l}\text { Recreation opportunities that I like to participate } \\
\text { in are not available at the WVU Rec Center }\end{array}$ & 1 & 2 & 3 & $\mathrm{~N} / \mathrm{S}$ \\
\hline Negative attitudes from employees & 1 & 2 & 3 & $\mathrm{~N} / \mathrm{S}$ \\
\hline \multicolumn{5}{|c|}{$\begin{array}{l}\text { Are there any other reasons you haven't recreated } \\
\text { at the WVU Rec Center as often as desired over the past year? } \\
\text { Please explain }\end{array}$} \\
\hline
\end{tabular}

13. Do you participate in Intramural programs?
口 Yes
回o

14. Do you participate in group exercise classes?
$\square$ Yes
$\square$ No 


\section{Next, we would like to hear about your overall experiences at the WVU Rec Center.}

15. How would you rate the overall quality of the Facilities at WVU Rec Center?

\begin{tabular}{|c|c|c|c|c|c|c|}
\multicolumn{1}{c}{} & $\begin{array}{c}\text { Not at all } \\
\text { Satisfied }\end{array}$ & $\begin{array}{c}\text { Somewhat } \\
\text { Satisfied }\end{array}$ & $\begin{array}{c}\text { Moderately } \\
\text { Satisfied }\end{array}$ & $\begin{array}{c}\text { Very } \\
\text { Satisfied }\end{array}$ & \multicolumn{1}{c}{$\begin{array}{c}\text { Extremely } \\
\text { Satisfied }\end{array}$} & $\begin{array}{c}\text { Not } \\
\text { Applicable }\end{array}$ \\
\hline Facilities & 1 & 2 & 3 & 4 & 5 & \\
\hline
\end{tabular}

16. How would you rate the overall quality of Services at the WVU Rec Center?

\begin{tabular}{|c|c|c|c|c|c|c|}
\multicolumn{1}{c}{$\begin{array}{c}\text { Not at all } \\
\text { Satisfied }\end{array}$} & $\begin{array}{c}\text { Somewhat } \\
\text { Satisfied }\end{array}$ & $\begin{array}{c}\text { Moderately } \\
\text { Satisfied }\end{array}$ & $\begin{array}{c}\text { Very } \\
\text { Satisfied }\end{array}$ & $\begin{array}{c}\text { Extremely } \\
\text { Satisfied }\end{array}$ & $\begin{array}{c}\text { Not } \\
\text { Applicable }\end{array}$ \\
\hline Services & 1 & 2 & 3 & 4 & 5 & \\
\hline
\end{tabular}

17. How would you rate the overall quality of Information at the WVU Rec Center?

\begin{tabular}{|c|c|c|c|c|c|c|}
\multicolumn{1}{c}{} & $\begin{array}{c}\text { Not at all } \\
\text { Satisfied }\end{array}$ & $\begin{array}{c}\text { Somewhat } \\
\text { Satisfied }\end{array}$ & $\begin{array}{c}\text { Moderately } \\
\text { Satisfied }\end{array}$ & $\begin{array}{c}\text { Very } \\
\text { Satisfied }\end{array}$ & \multicolumn{1}{c}{$\begin{array}{c}\text { Extremely } \\
\text { Satisfied }\end{array}$} & \multicolumn{1}{c}{$\begin{array}{c}\text { Not } \\
\text { Applicable }\end{array}$} \\
\hline Information & 1 & 2 & 3 & 4 & 5 & \\
\hline
\end{tabular}

18. On a scale of $\mathbf{1}-\mathbf{1 0}$, how would you rate your overall quality of experience of the WVU Rec Center for a typical visit?

\section{Finally, we'd like to know a little about you.}

19. Are you Hispanic or Latino $\square$ No $\square$ Yes

20. Which racial group(s) do you identify with? Check all that apply.
四hite
$\square$ Black/African American
口Asian
口American Indian/ Alaska Native QNative Hawaiian or other Pacific Islander

21. Gender: 回 Female $\square$ Male

22. What is your current enrollment status here at WVU?

$\square$ I am enrolled full time (12+ credits)

$\square$ I am enrolled part time ( $<12$ credits)

23. How many semesters including the current semester have you attended at WVU?

24. Where do you live while attending school at WVU?

$\square$ In the dorms/campus apartments

$\square$ At home

$\square$ Off campus housing 
25. Are you currently employed (pick one)?
口 Yes, I work full time
$\square$ Yes, I work part time
口 No, I don't currently work

26. What positive comments do you have about the WVU Rec Center?

27. What improvements would you suggest for the WVU Rec Center? 


\section{West Virginia University - Summary of Positive Comments}

\section{What positive comments do you have about the Recreation Center?}

A lot of exercise machines and free weights which is nice, the cardio machines are top notch. The pool is very appealing and a ton of BB courts.

Always clean and fitness trainers are good.

Awesome hours

Awesome rock wall

Can do multiple things at the center.

Clean and its location is reasonable.

Convenient hours

Courts and equipment in good condition

Free classes is great, I love Zumba, great staff.

Good customer quality

Good intramural programs

Great basketball courts

Great equipment, I've already seen results on me.

Great place to relieve stress

Great pool and fitness area

Has everything you would possibly need to work out.

I like the work out classes they offer. The instructors are very motivated.

It helps me stay in shape and makes me feel good about myself.

It is a big reason why I chose to come to WVU.

It is a nice facility but overcrowded sometimes.

It is a well rounded place to go when one feels the need to achieve real healthy status.

It provides me with weights and machines I need to exercise and is a great place to meet new and old people and friends.

It's a great place for people to interact with others and make exercising fun.

It's a place to go where you can be yourself and don't have to worry about a thing.

Organized, clean

Outdoor rec center is awesome

Pool area is my favorite part of the rec center, most undervalued in my opinion.

Provides multiple things to do for exercise. It is the nicest university center I have seen so far.

The pool and staff down there are top notch.

The climbing wall is awesome and full of wonderful staff.

The music is nice and upbeat, it encourages me to work out

Very accessible

Very good place-not intimidating

Yoga is good 


\section{West Virginia University - Summary of Improvements}

\section{What improvements would you suggest for the Recreation Center?}

Longer hours, more weight machines, more water fountains, hit music or techno.

A way to control the crowds would be great. It's always congested.

Ability to play soccer or volleyball in the center.

Add more badminton courts

Add new squat machines

An outdoor turf field for pick-up football, soccer, lacrosse games

Better locker rooms and more machines (treadmills)

Better quality basketballs

Better security

Bigger weight room

Build one downtown

Card/student look-up in case students forget

Crowded weight room at peak hours, boring track

Deeper pool end, more evening times for classes such as spinning

Disinfecting machines

Do something to improve parking and the crowd in the weight room

Expand facilities

Fix the toilets in the women's locker room. Fix the machines by the rock wall, not much work anymore.

Fix the water fountains, they have not worked for 2-5 years.

Full time staff in weight room

Get a sauna

Get more weights because so many people like to use them.

Get more utilities such as belts for squatting in the weight room.

Get rid of Badminton

Olympic platforms could be useful for weight lifting

Hockey rink

I don't have many, except to maybe have a suggestion box.

I wish it was open later on Sunday, this is the best day for me to go

Improve or fix locking mechanism in the lockers

It would be nice thave a steam room

Keep it open on Sunday's

Keep the cafe open longer

Larger weight room, machines with heavier weight, more unique machines.

Make sure all equipment stays in good condition downstairs.

Overall smell is bad

Maybe have signs where certain equipment so fewer people won't get lost.

More aquatic activities 
More classes aimed toward men. Woman have Zumba, yoga, spinning and self defense which men do not usually attend. Cool to see classes appeal to the guys, maybe a boxing class or male exercise class.

More elliptical machines

More equipment in free wt/treadmill area. get hammer strength, model equip after sports teams; many people want to work out how they see teams \& TV shows (UFC) Train student workers.

How to handle emergencies (seizures), I have seen them not treat emergencies correct.

More info out about intramurals

More machines, more yoga, move zumba to the coliseum and free up some parking.

More parking spaces

More up to date machines or recalibrate to correctly calculate calories, heart rate, etc.

Cardio machines often broken

More visible and helpful fitness staff, sometimes it is frustrating to see all they're doing is homework. Moving Zumba back to where it use to be with the convenience of the bathroom and water fountains.

Negative comments are parking and open machines

No lounge areas available to sit and relax

Non-irritable staff, more lockers, kettle bells and rooms to use them.

Open at $5 \mathrm{am}$

Open later at night

Perhaps offer brochures on losing weight/staying fit both in and out of the rec center.

Soccer facilities please!!!

Spotter for free weights would be helpful for shy and new free weight lifters.

Staff could be nicer

The only thing I can think of is security, more has been stolen. I know you can't control people but try to catch them.

Wireless internet, get TV in lobby by ORC working. 